\title{
EXPERIMENTAL INVESTIGATION ON CONCRETE FILLED STEEL TUBULAR COLUMN TO FOUNDATION CONNECTIONS SUBJECTED TO COMBINED AXIAL AND LATERAL CYCLIC LOADING
}

\author{
Jothimani. $\mathrm{B}^{\mathrm{a}^{*}}(\mathrm{D}$ \\ Umarani.C $C^{\mathrm{a}}$ iD \\ a Department of Civil Engineering, Anna University, Chennai, India. E-mail: jothimn05@gmail.com, umarani@annauniv.edu \\ * Corresponding author
}

http://dx.doi.org/10.1590/1679-78255629

\begin{abstract}
This study focuses on performance of CFT column to foundation connections subjected to combined axial and lateral cyclic loading. Experimental investigations were carried out on five specimens with exposed column base and embedded column base connections. The parameters considered were number of stiffeners and embedment depth of CFT column. The force - displacement response of all the specimens were compared. Providing increased number of stiffeners, increase the strength of connection. An additional mesh provided on the embedded connection was found to be good in improving the ductility of the connection which is a feasible solution for composite structures in earthquake prone regions.
\end{abstract}

\section{Keywords}

Concrete filled steel tubes, column bases, lateral cyclic loading, stiffeners

\section{INTRODUCTION}

Composite construction is gaining importance and have been widely used now-a-days in the construction industry. The most common types of composite sections are the steel reinforced concrete column (SRC), which is cast by encasing a structural steel section in concrete and the concrete-filled steel tube (CFT) column. Concrete filled steel tubular columns have many advantages and better structural properties, such as high strength under compression loading, enhanced ductile behaviour and good capacity in terms of energy absorption. Due to their large compressive stiffness and axial-load carrying capacity, CFTs are also used for piers, columns, and caissons for deep foundations[Faschan (1992) and Viest (1992)]. Numerous studies were carried out for CFT columns to improve the rigidity, and enhance the design efficiency of CFT structural sections[Furlong (1967), Neogi et al. (1969), Knowles and Park (1970), Tomii et al. (1977) ]. With the improvement in ductile behaviour, these composite columns perform well under seismic loading. CFT columns are very well suitable for construction of tall buildings [Matsumoto et al. (2014)] and structures in seismic vulnerable zones.

In composite construction, connections are the most critical zone as several structural members will get affected during failure of a single connection. In 1990, Northridge and Kobe earthquakes, it was reported that many failures were found in the connections. Hence utmost care should be taken while designing a structural connection. Considering all typical structural connections, column to foundation connection is the most critical part in the design of such composites. Even though these sections possess enhanced structural performance, their usage is very less due to the lack of knowledge and experience on the behavior of these members under various loading scenarios and also due to the lack of codal provisions.

CFST column to foundation connections were broadly classified as exposed and embedded connections. In exposed connection, the column-base is usually above the foundation concrete. In embedded column-base connections, the 
column is partly embedded inside concrete, the base moment is mainly resisted by bearing between the column and the surrounding concrete. Inelastic cyclic tests were carried out to evaluate the ultimate strength and ductility of CFST piers connected to the foundation as shown in Figure 1(a) [Marson and Bruneau (2004)]. The new foundation concept was introduced to achieve the full fixity of the connection. The bottom plate was connected with the top plate using channel sections on either side. A hole was created in top plate for the insertion of CFT columns. The ductility of all connections was found to be good and could reach maximum drifts of $7 \%$ before a significant loss in moment capacity. This type of connection was not suitable for larger diameter columns because the selection of channels depend on size of the column and therefore expensive. To evaluate the seismic performance of embedded CFT column-base connections, experiments carried out [Moon et al. (2013)]. Monolithic and recessed embedded connections were introduced [Figure 1(b) and (c)]. The former connection consisting of an annular ring (or flange) welded to the base of the tube and embedded directly into the foundation. The later connection was isolating the CFT by light corrugated steel pipes. Composite action was achieved by filling the pipes with high pressure grout. It was reported that specimens with the longer embedment length had higher drift capacities far in excess of the maximum seismic design drifts without damage to the footing. Cui et al. (2015) aimed to study the shear behaviour of exposed column bases. The main parameters considered were the number of anchor rods, position of anchor rods and the level of axial and lateral loading. It was observed that, the current design approach underestimated the shear resistance of the connection.

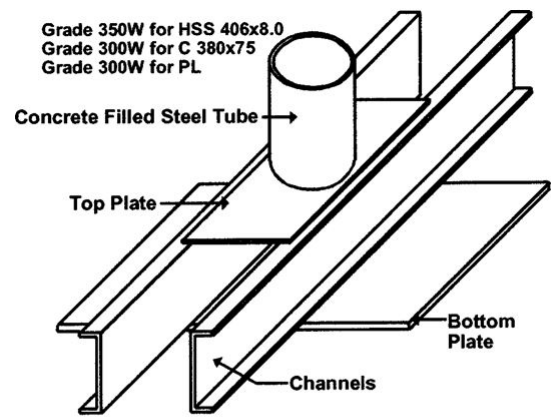

a) Embedded connection

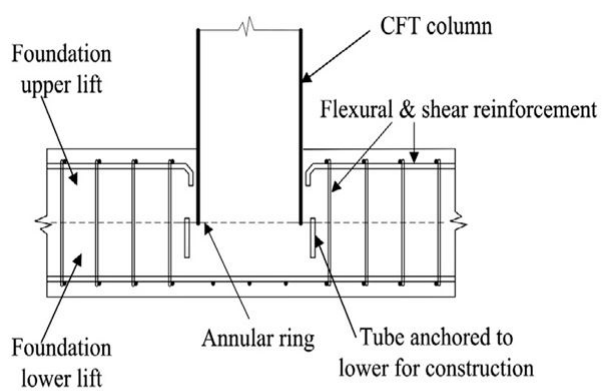

b) Monolithic connection

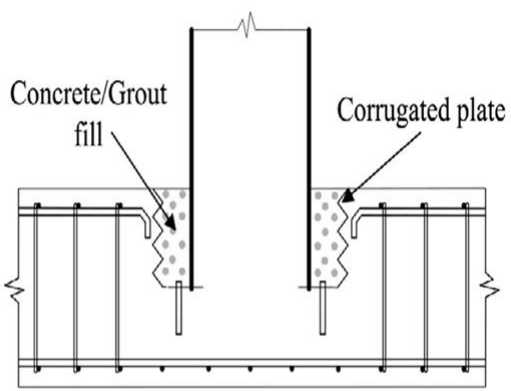

c) Recessed connection

Figure1 Composite Connection - Previous studies.

Pertold et al. (2000) carried out both experimental and numerical investigations on the behaviour of embedded steel column bases. The numerical results were validated with the test results. Simulation of the embedded column base plate has revealed that the resistance of an embedded column base is approximately $15 \%$ higher than that of a column base with the base plate placed on the concrete surface. Moon et al. (2012) developed an analytical model for the embedded column base connections. Also, with a validated model in hand, a parametric study was performed to study the effects of $D / t$ ratio, embedment length, shear reinforcement ratio, concrete compressive strength ratio of the footing and infill in the CFT, and axial load ratio. Hitaka et al. (2003) studied the behaviour of connections with different types of base plates. This connection was possible only when smaller moments were transferred to the plate. Transfer of larger moments led to serious damage to the base plate. Hsu and Lin (2006) investigated the seismic behaviour of square CFT column foundation connections. Embedment length was varied as $0.5 \mathrm{D}, 1 \mathrm{D}$ and 1.5D (where $\mathrm{D}$ is the diameter of CFT column) and rectangular stiffener plates were attached to all the sides of the embedded columns. The specimen with embedded depth 1D achieved large inelastic deformation and slight improvement was noted in 1.5D specimen. Hence in the present study, experimental investigation on performance of column foundation connections under lateral cyclic loading was carried out with an aim to propose a new connection with better energy dissipation capacity.

\section{DETAILS OF STUDY CARRIED OUT}

Five types of column-foundation connection specimens were cast and tested experimentally under lateral cyclic loading. To understand the behaviour of composite column-foundation connections, two specimens 1) exposed-base connection 2) embedded-base connection with 1D depth of embedment were tested experimentally. From the results, the embedded connection exhibited better performance. To improve the embedded connection with less embedment depth, three specimens were cast, varying the following parameters number of stiffeners, stiffener arrangement and a reinforcement mesh around the CFST columns. The load-displacement responses of all the specimens were presented in 
detail. The load-displacement curve will enclose an area, referred to as the hysteresis loop that is proportional to the energy loss per cycle. The energy dissipation of the specimens were calculated by finding the area enclosed by the hysteresis loop in each cycle of loading.

\section{EXPERIMENTAL PROGRAM}

Behaviour of five different types of CFST Column - base connection were studied experimentally under lateral cyclic loading. All the specimens had the same diameter circular CFST columns filled with concrete of same grade but with the following parameters varied. (i) Depth of embedment and (ii) provision of stiffeners. The details of the test specimens are as follows,

1. CFST column- base connection with zero depth of embedment and with 4 stiffeners at column base plate connection. CFST-0D-4S-01[Figure 2(a)]

2. CFST column-base connection with depth of embedment of $1 \times D$ (where $D$ - Diameter of CFT column) and with 4 triangular stiffeners at column base plate connection. CFST-1D-4S-02 [Figure 2(b)].

3. CFST column-base connection with depth of embedment of $0.75 \times \mathrm{D}$ and with 4 stiffeners at column base plate connection. CFST-0.75D-4S-03[Figure 2(c)].

4. CFST column-base connection with depth of embedment of $0.75 \times \mathrm{D}$ and with 8 stiffeners at column base plate connection. CFST-0.75D-8S-04 [Figure 2(d)] and

5. CFST column-base connection with depth of embedment of $0.75 \times \mathrm{D}$ and with 8 stiffeners at column base plate connection and with a layer of mesh of $12 \mathrm{~mm}$ diameter bars around the CFST column. CFST-0.75D-8S-M-05 [Figure 2(e)]. 


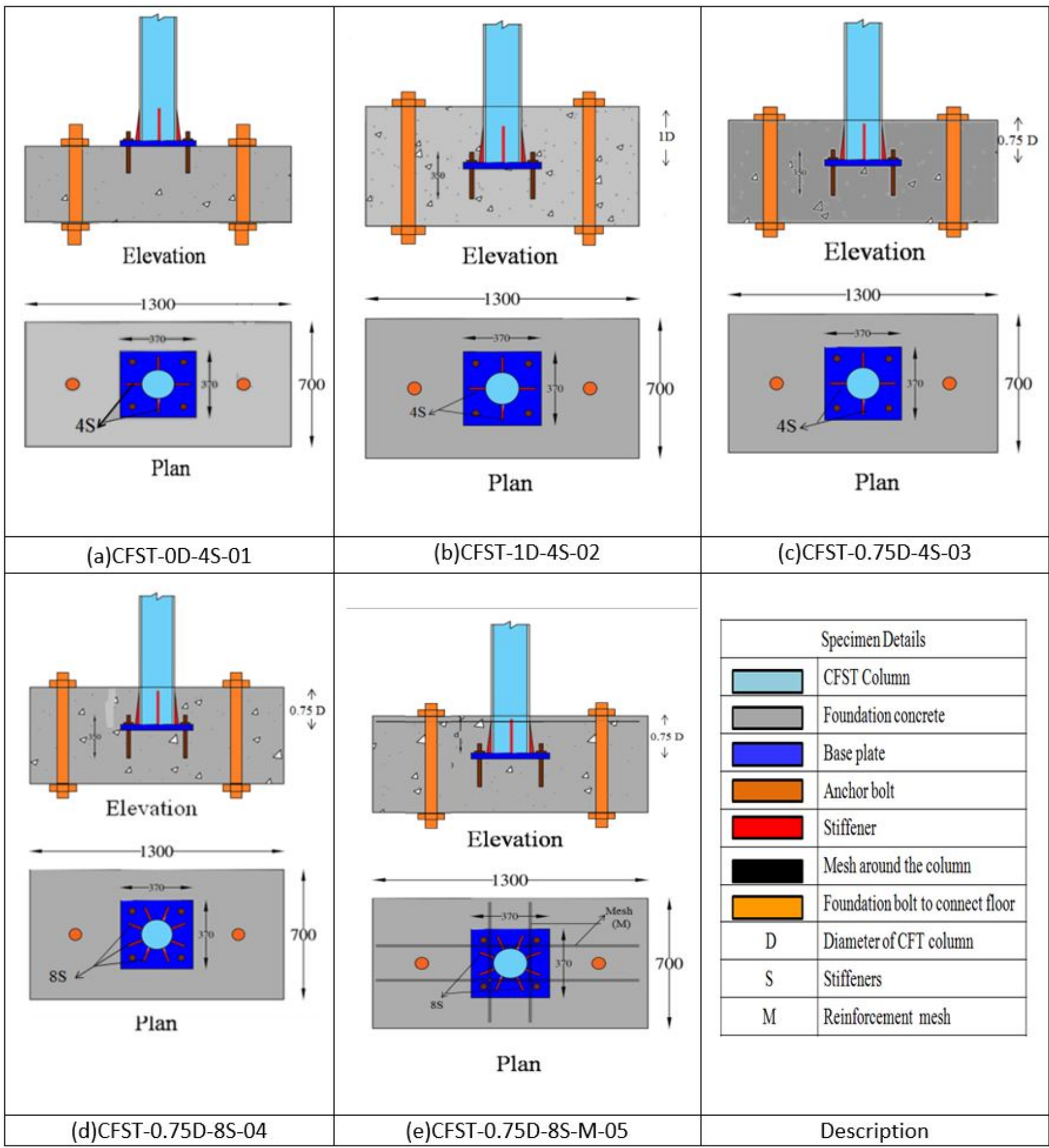

Figure 2 Specimen Details Elevation and plan.

\subsection{Casting of Specimens}

Casting of all the five test specimens were carried out as detailed below. Each specimen consisted of a CFST column and a reinforced concrete foundation. The steel tube of CFST had $165.1 \mathrm{~mm}$ outer diameter with $4.8 \mathrm{~mm}$ thick of grade Fe250. The base plate of size $370 \times 370 \times 32 \mathrm{~mm}$ was used. The design of CFST column - foundation was done in such a way that the failure of connection would not occur in the base plate, thereby avoiding yield of the base plate till the failure of the specimen. $18 \mathrm{~mm}$ diameter bolt holes were provided in the base plate for inserting the anchor bolts. Anchor bolt ASTM A325 M16 of length 350mm was provided for all the specimens. Bolts were designed to yield, when the CFST column reached its full capacity. Triangular plate stiffeners of size $100 \times 100 \times 2 \mathrm{~mm}$ were welded to the steel tube -base plate connection. For specimens CFST-0D-4S-01, CFST-1D-4S-02 and, CFST-0.75D-4S-03 four numbers of stiffeners were 
arranged parallel and perpendicular to the direction of loading. For specimens CFST-0.75D-8S-04 and CFST-0.75D-8S-M05 , eight numbers of stiffeners were provided with equal spacing. Steel tubes for CFT column, welded with stiffeners and base plate are shown in Figure 3(a).

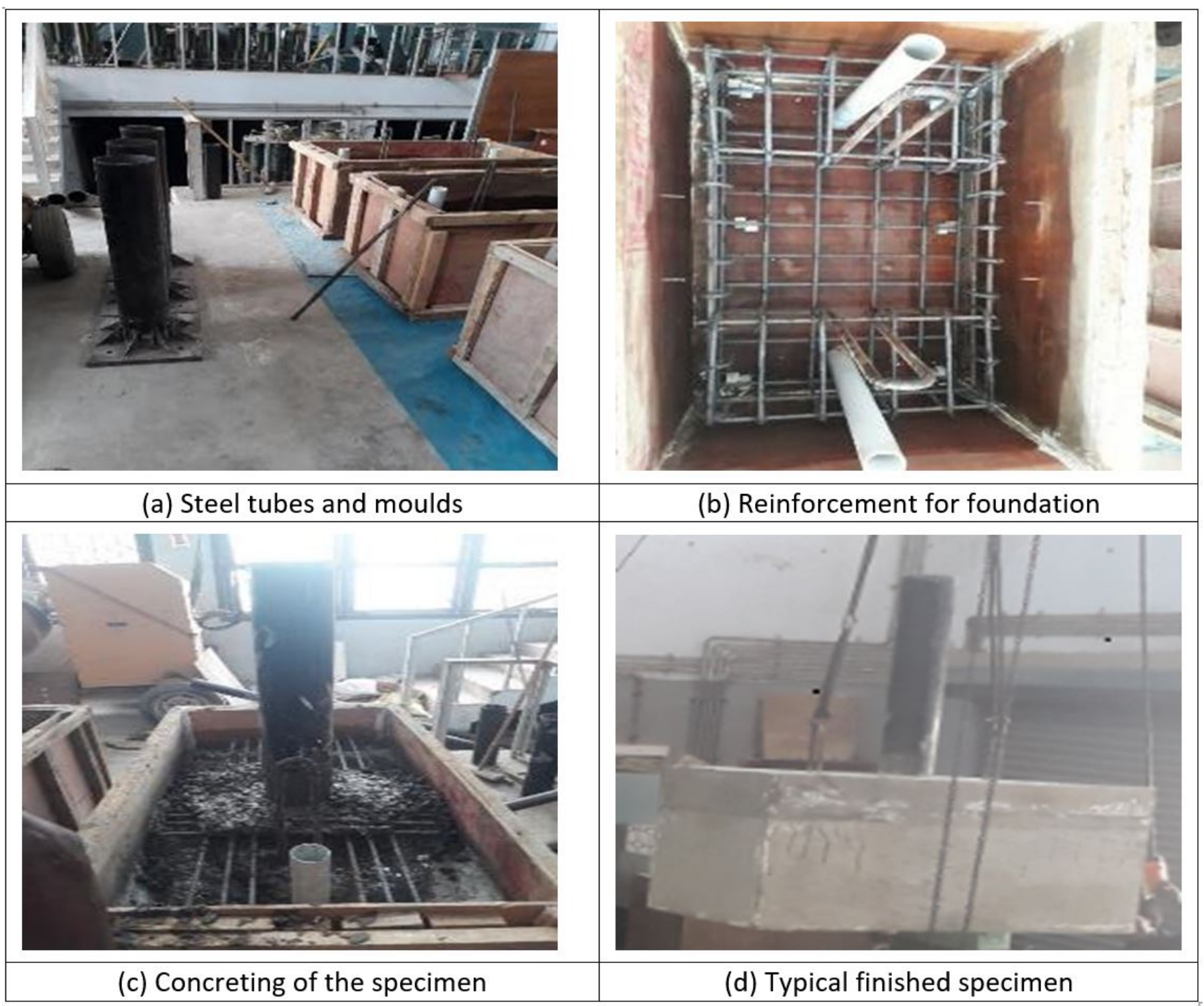

Figure 3 Casting of the specimens.

After the fabrication of steel tube, foundation concrete was prepared. The size of the foundation was fixed as $1300 \mathrm{~mm}$ length $700 \mathrm{~mm}$ width. The size was so chosen to make it suitable for fixing it firmly to the strong test floor. The height of the foundation was varied due to the embedment depth of column. Nominal reinforcement was provided in the foundation concrete with $12 \mathrm{~mm}$ diameter bars. The formwork for the foundation was made and the reinforcement was placed inside the formwork [Figure 3(b)].

For exposed connection specimen CFST-0D-4S-01, the casting was done in single pour for mounting the anchor bolts in the reinforced concrete foundation. After the anchor rod got rigidly fixed, i.e. after 15 days the CFST column was placed on the foundation and the bolts were fastened.

For embedded connection, the concrete pouring was done in two stages. First pour was similar to the exposed connection. Non-shrink grout was applied between the base plate and the existing concrete footing to ensure proper filling. The second pour was to complete the foundation with the mentioned embedded depth for the embedded specimens along with infilling the steel tube with concrete is shown in Figure 3(c).

Water curing was done for the first and second pouring of concrete. Self-curing agent CONCURE WB was applied for CFST column. The average compressive strength was obtained from the cube test. Compressive strength of concrete 
for first and second pouring were $32.9 \mathrm{~N} / \mathrm{mm}^{2}$ and $34.6 \mathrm{~N} / \mathrm{mm}^{2}$. Figure $3(\mathrm{~d})$ shows a CFST column - foundation connection specimen being shifted to the test floor.

\subsection{Test Setup and Measurements}

The specimens were tested using a self-straining frame which is rigidly connected to the strong floor and the frame has provisions for applying constant vertical and horizontal loading to the specimen. The specimen was fixed to the strong test floor using the high tension steel bolts, and the required provisions for fixing the specimen on the test floor were already provided while casting the foundation. The axial load was applied to the column top using a servo controlled hydraulic jack of $500 \mathrm{kN}$ capacity supported on a loading beam. A double acting servo controlled hydraulic jack of $200 \mathrm{kN}$ capacity was fixed to the reaction frame and the lateral cyclic load was applied under displacement control. Schematic representation of the test setup is as shown in Figure 4. The anchor bolts connecting the column and the foundation concrete was instrumented with linear electrical resistance strain gauges for strain measurement during testing. These strain gauges were protected properly to prevent them from getting damage during concreting. Displacement transducers were used for measuring the horizontal displacement of the column. Load cells were used to measure the lateral force of the specimen. The instrumented strain gages were connected to a microprocessor based high speed data acquisition system. The displacement transducers and the load cells were also connected to the data logger DEWESOFT 7.0.1 and the responses were measured continuously throughout the testing.

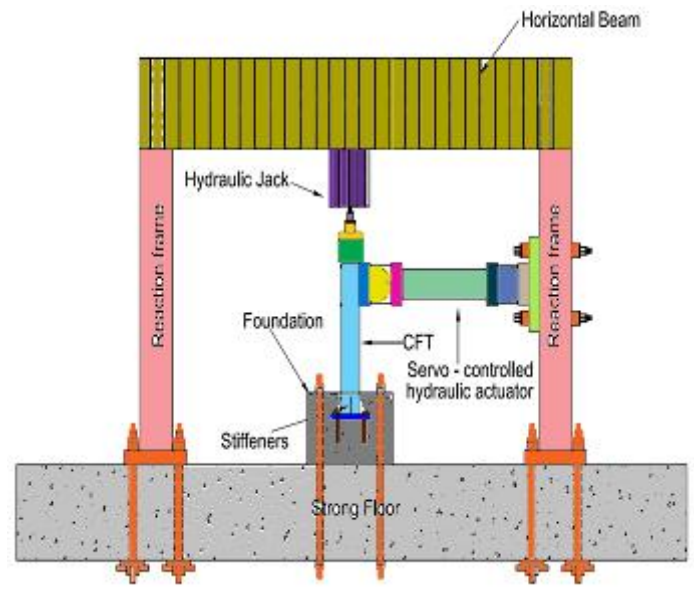

Figure 4 Schematic representation of the test setup.

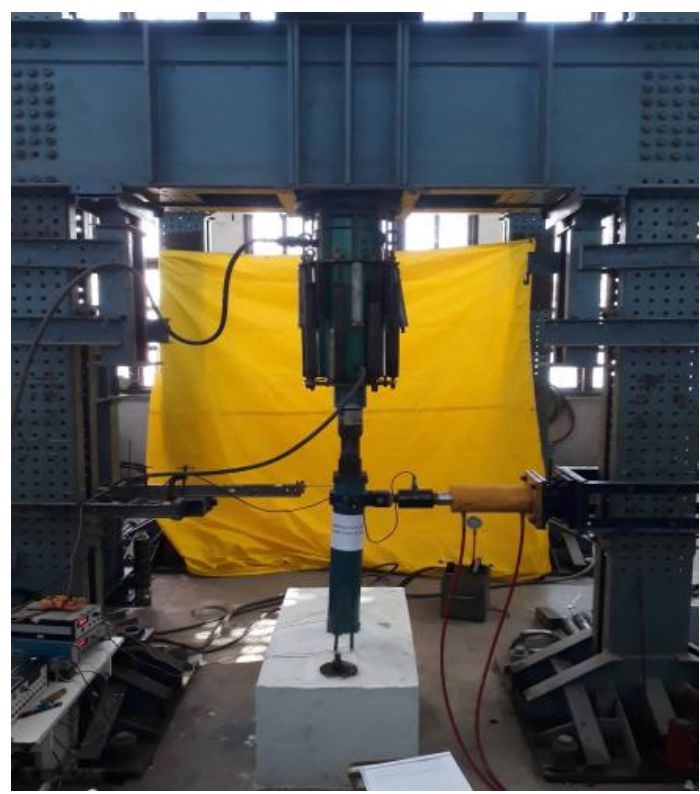

Figure 5 Testing of Specimen.

A constant axial load was evaluated as $10 \%$ of the concrete filled column's compressive strength using the equation 
where $A_{c}, A_{s}$ are the cross sectional areas of infilled concrete and the steel tube; $f_{c}{ }^{\prime}$ and $F_{y s}$ are the compressive strength of concrete and the yield strength of the steel tube. Initially, axial load was applied to the specimen and kept constant. Typical test specimen with test setup kept ready for testing is as shown in Figure 5. The loading history with incremental displacement cycles in terms of drift ratio was as shown in Figure 6. All the specimens were tested in the same manner until failure. The Load - Displacement response of the tested specimen was monitored using the Dewesoft presented in Figure 7.

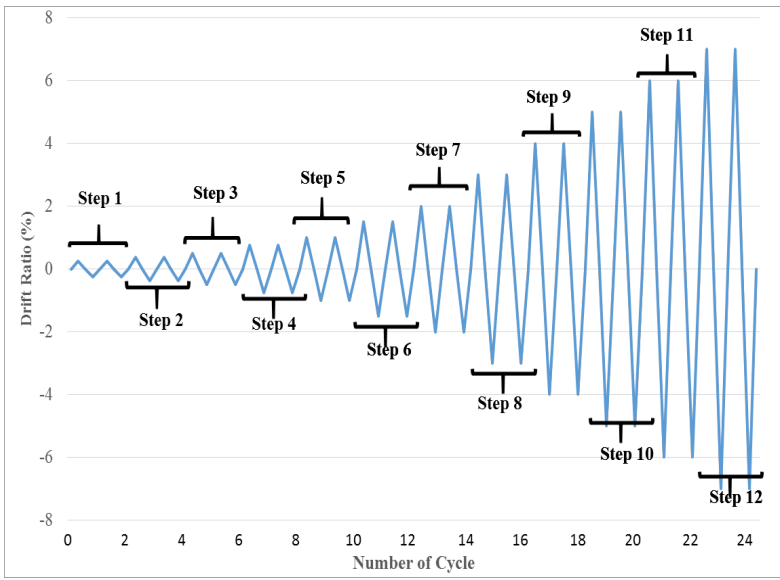

Figure 6 Loading history.

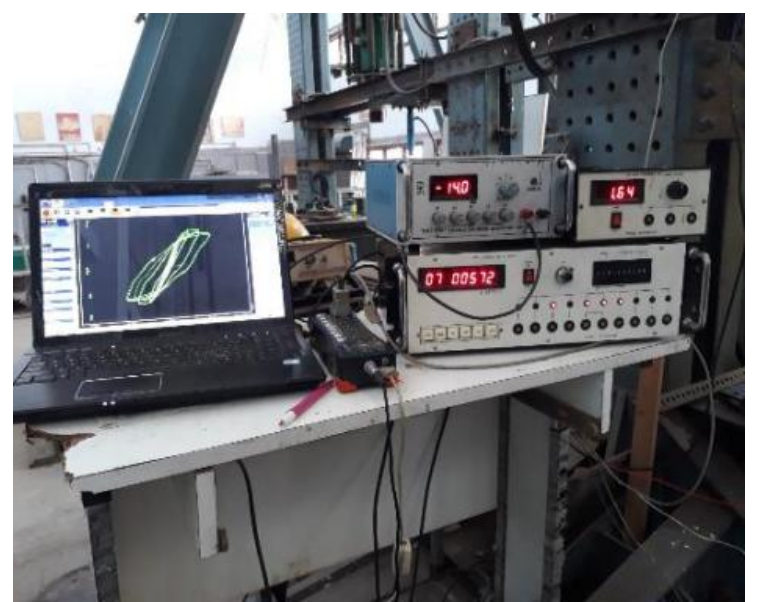

Figure 7 Load - Deflection Curve of tested specimen from Dewesoft.

\section{OBSERVSATIONS}

The hysteretic behaviour of each of the tested specimens at $1 \%, 3 \% 5 \%$ and $7 \%$ drift levels are presented below.

\subsection{Exposed Column - Foundation Connection - CFST-0D-4S-01}

This specimen designated as CFST-OD-4S-01 is CFST column -foundation connection with zero depth of embedment and with four stiffeners as shown in Figure 2(a). Displacement controlled lateral cyclic load on the top of column specimen with constant axial load of 16kN was applied as shown in Figure 4 and 5. The loading history is shown in Figure 6.

In the initial stages, the exposed CFST column connection behaved well. The axial load initiation did not produce any visual observation. After the introduction of lateral load, the load-displacement response was linear upto $0.75 \%$ of drift. At $1 \%$ drift, minor hair line cracks on the foundation concrete was observed as shown in Figure 8. 


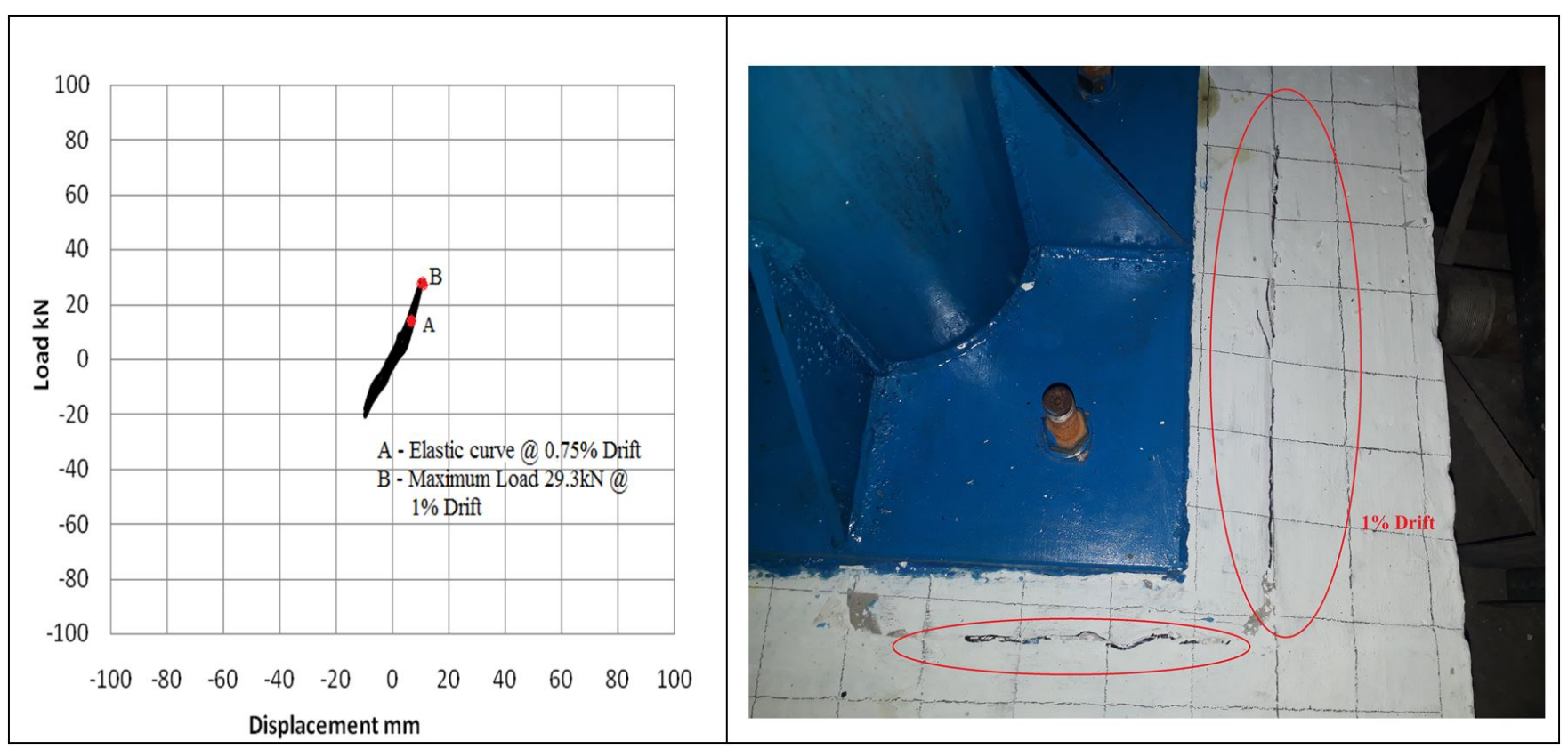

Figure 8 Exposed column - foundation connection CFST-0D-4S-01 at 1\% Drift.

After $1.5 \%$ drift, when the load was $30.8 \mathrm{kN}$, cracks near the interface of base plate and foundation concrete were noticed. At the same time, the minor cracks in the foundation concrete was extended. The foundation concrete crack was initiated as a hair line crack of width $2 \mathrm{~mm}$ (Figure 9). Spalling of concrete was noted in the foundation concrete at $3 \% \mathrm{drift}$.

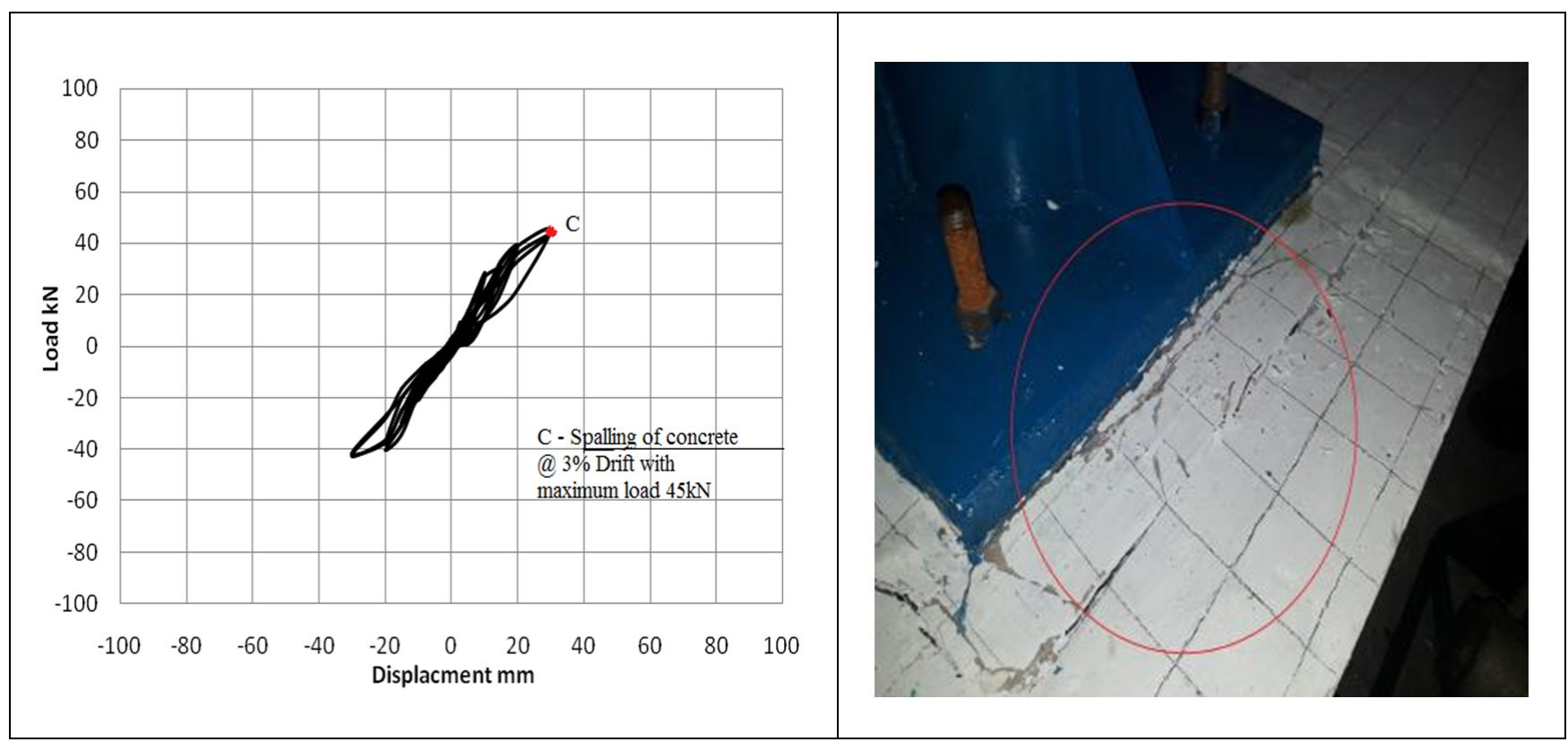

Figure 9 Exposed column - foundation connection CFST-0D-4S-01 at 3\% Drift.

At $4 \%$ drift, the width of cracks around the base plate and foundation concrete was increased up to $6.5 \mathrm{~mm}$. The bond between the interface of CFST column and the foundation was decreased slowly and the anchor bolts in exposed column connection exhibited yielding shown in Figure 10(a). Severe damage occurred on the foundation concrete at $5 \%$ drift [Figure 10(b) and (c)]. After 5\% drift, the connection reached a peak load of $52.6 \mathrm{kN}$. The load-displacement curve was presented in Figure 10(d). 


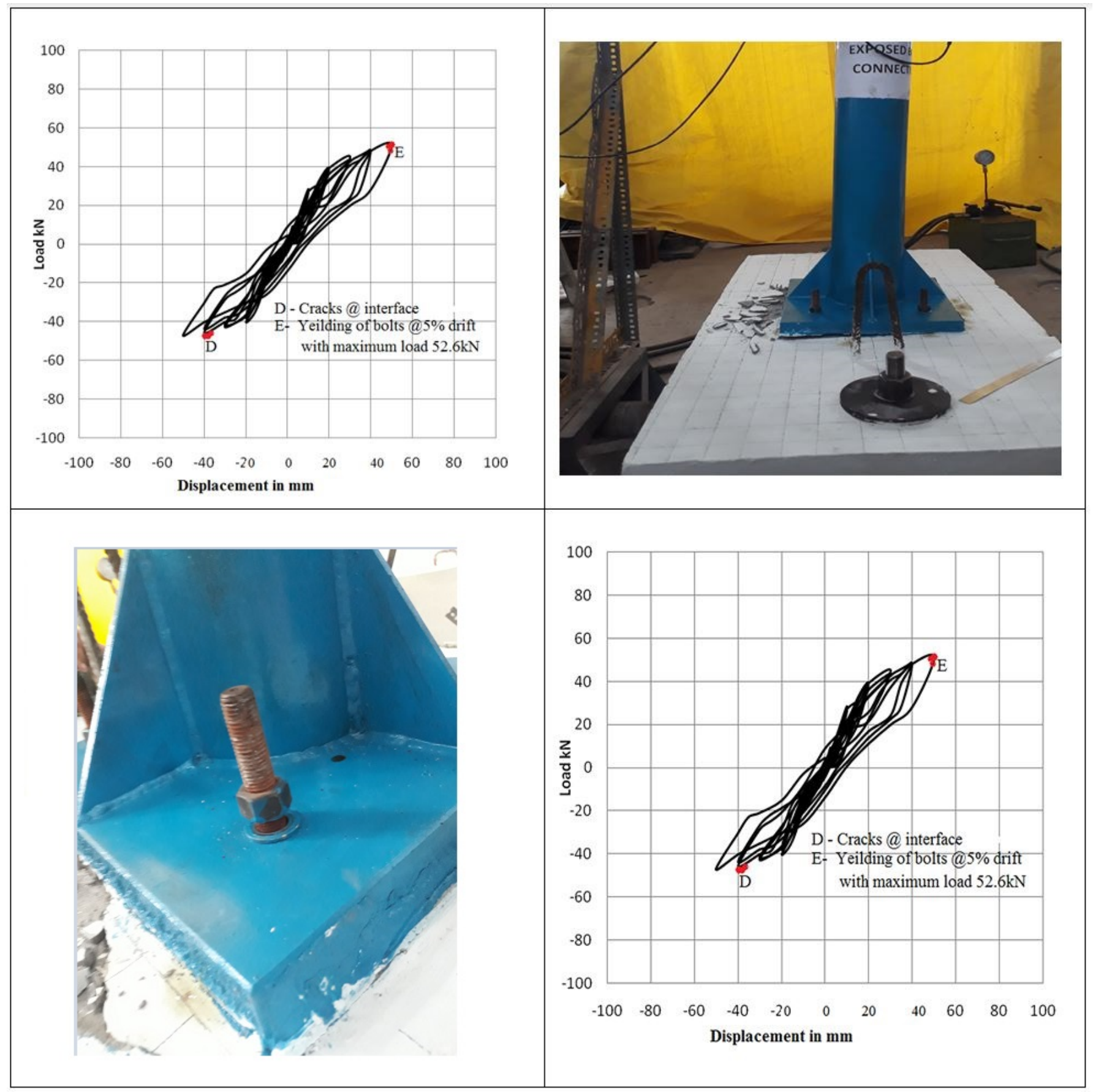

Figure 10 Exposed column - foundation connection CFST-0D-4S-01 (a) Yielding of anchor bolts (b) Damage noticed on foundation concrete (c) Interface between baseplate and foundation (d) Load-displacement at 5\% Drift

\subsection{Embedded Column - Foundation Connection - CFST-1D-4S-02}

The specimen designated as CFST-1D-4S-02 is a CFST column-foundation connection with depth of embedment of 1D and with four stiffeners at column-base plate connection as shown in Figure 2(b). Displacement controlled lateral cyclic load on the top of column specimen with constant axial load was applied as shown in Figure 4 and 5 . The loading history is shown in Figure 6.

At the beginning of the test, the specimen displayed a slender straight line in the data logger, which defined a linear behaviour [Figure 11(a)]. At $1 \%$ drift, the corresponding load was found to be $27.6 \mathrm{kN}$. At $3 \%$ drift, the specimen achieved a maximum yield load of $71.1 \mathrm{kN}$. But the foundation concrete was intact and no cracks were identified near the interface of column foundation connection. The hysteresis loop was changed from elastic to elasto - plastic stage after $1 \% \mathrm{drift}$ level [Figure 11(b)]. 


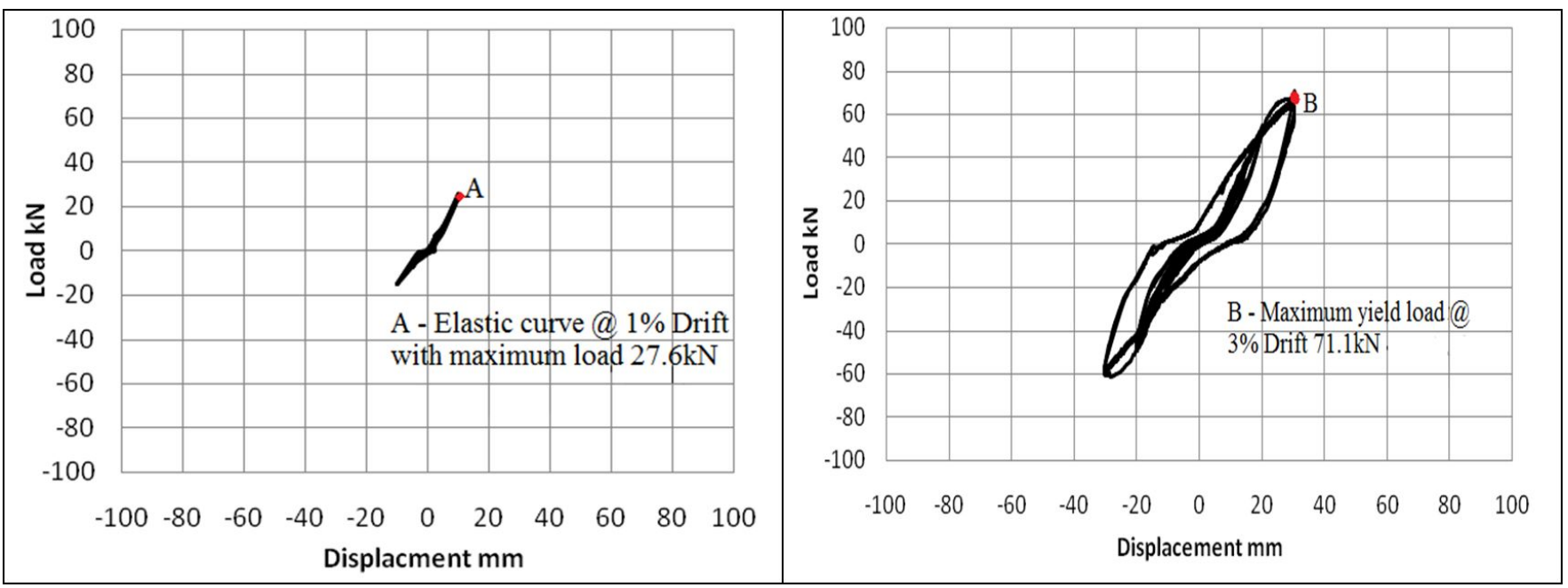

Figure 11 Embedded column - foundation connection CFST-1D-4S-02 at

(a) $1 \%$ and (b) $3 \%$ Drift.

At $4 \%$ drift level, very small cracks were found in the foundation concrete [Figure 12(a and b)]. At 5\% drift, no notable damages were located. The load started decreasing from the peak load. The length of cracks in the foundation concrete was not extended but elastic buckling started occurring.

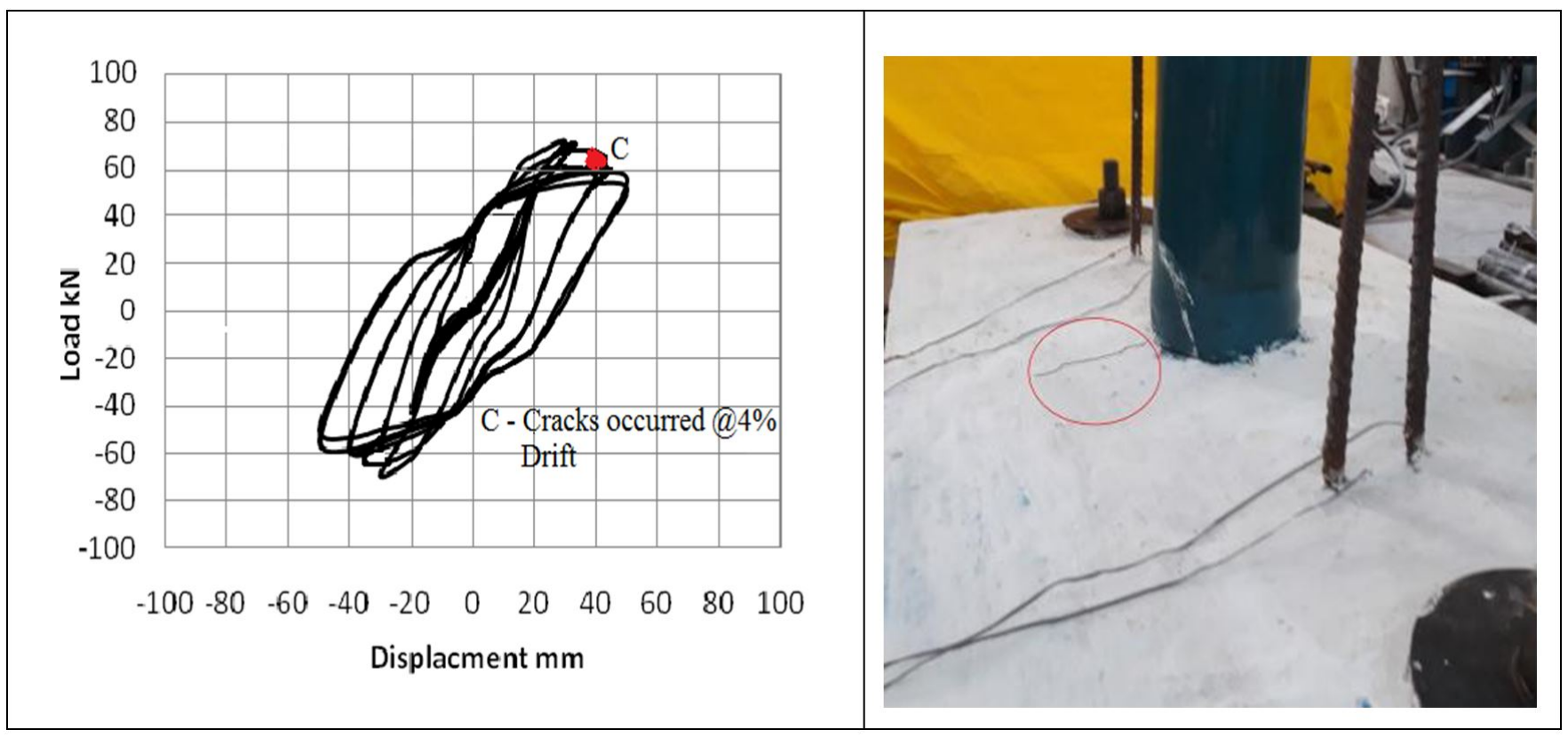

Figure 12 Embedded column - foundation connection CFST-1D-4S-02

(a) Load-displacement at 5\% Drift (b) Cracks at 5\% Drift.

Load- displacement response was presented in Figure 13(a). At 5\% drift level, local buckling was found on the left side of CFST column and the corresponding load was $48.7 \mathrm{kN}$ [Figure 13(b)]. This buckling of steel tube propagated on the right side of the column when pull load was applied [Figure 13(c)]. when the load was released, local buckling of column got diminished. Elastic buckling of column got extended [Figure 13(d)]. Finally at $7 \%$ drift, the column reached the inelastic buckling on both sides with the strength degradation and the corresponding minimum load was of $37.7 \mathrm{kN}$. 


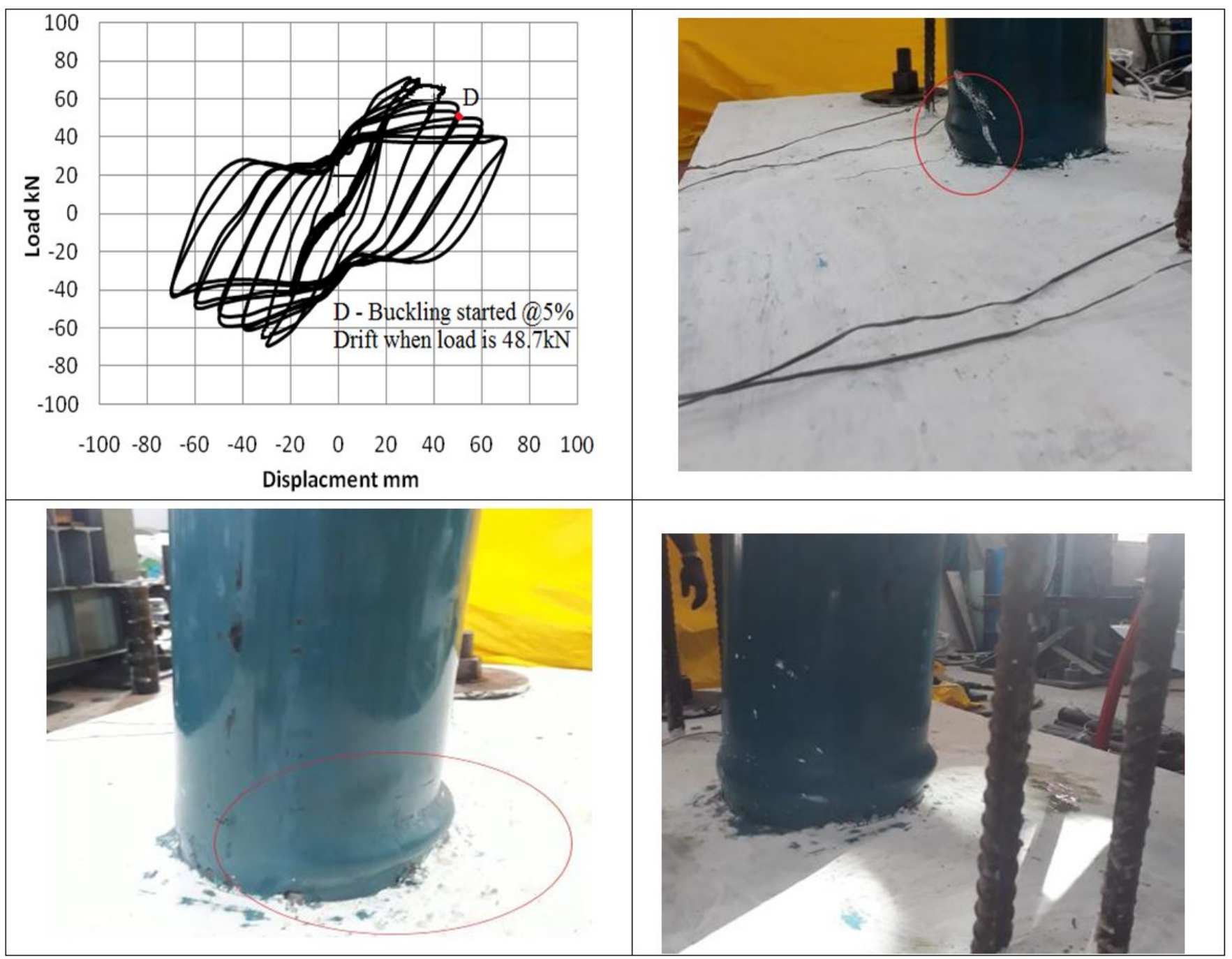

Figure 13 Embedded column - foundation connection CFST-1D-4S-02 (a) Load-displacement at 7\% Drift (b) Buckling noticed on left side of column (c) Buckling noticed on right side of column (d) Inelastic buckling occurred at $7 \% \mathrm{drift}$.

\subsection{Embedded Column - Foundation Connection - CFST-0.75D-4S-03}

The specimen designated as CFST-0.75D-4S-03 is a CFST column-foundation connection with depth of embedment of $0.75 \mathrm{D}$ and with four number of stiffeners at column-base plate connection as shown in Figure 2(c). Displacement controlled lateral cyclic load on the top of column specimen with constant axial load was applied as shown in Figure 4 and 5 . The loading history is shown in Figure 6.

At the initial stages of loading, no damage was observed until the drift level reached $1 \%$ drift [Figure 14(a)]. After that, in the base concrete, minor longitudinal cracks were formed. These cracks with length of $140 \mathrm{~mm}$ were nearly parallel and perpendicular to the direction of loading. The load-displacement curve was an elastic straight line with a maximum of $23.1 \mathrm{kN}$. Upto $2 \%$ Drift level, the load-displacement curve was elastic. After $2 \% \mathrm{drift}$, there was deviation in the load- displacement curve [Figure 14(b)]. During the 2 nd cycle of push load at $3 \%$ drift, the crack was noticed between the interface of the CFST column and foundation connection. The maximum load reached at $3 \%$ drift was found to be $66.9 \mathrm{kN}$. 


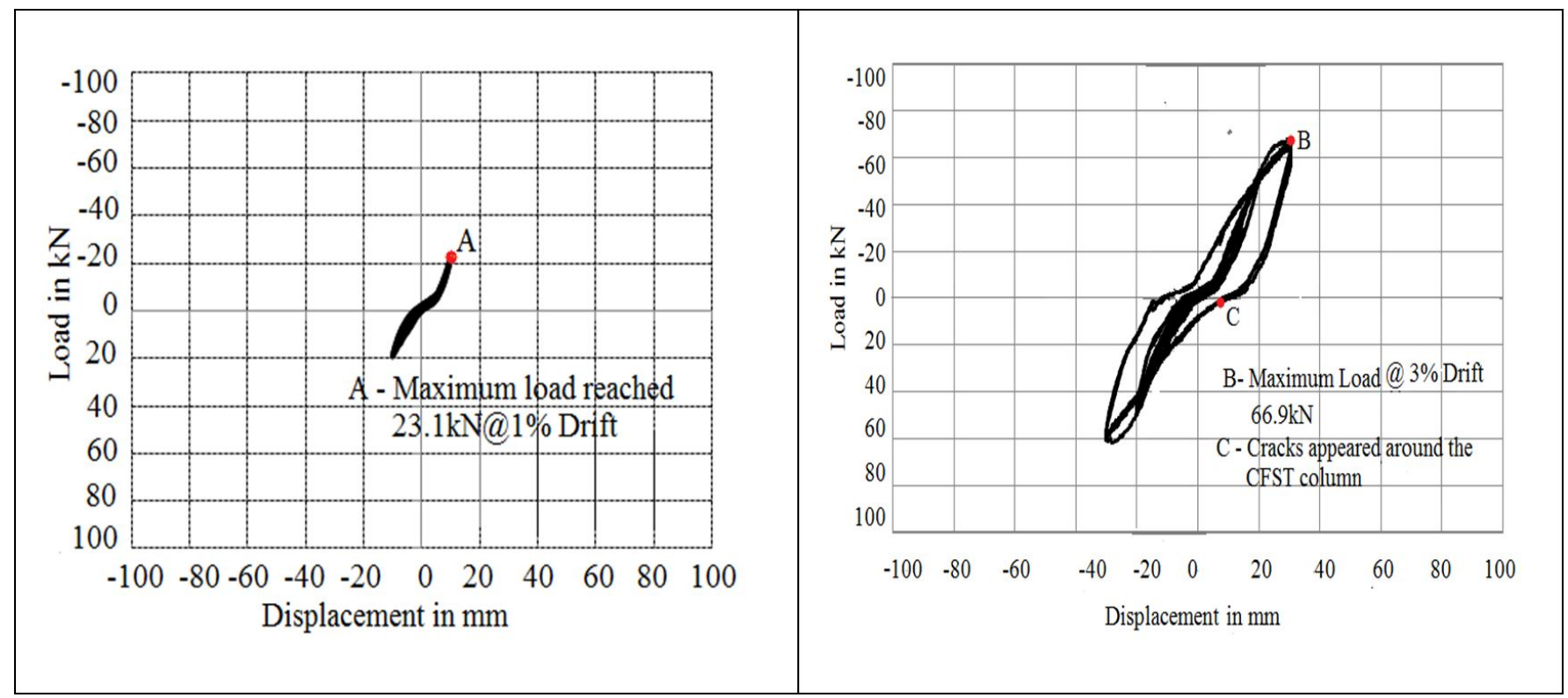

Figure 14 Embedded column - foundation connection CFST-0.75D-4S-03 at a) 1\% Drift b) 3\% Drift.

In the subsequent drift levels, width of crack around the column was increased. After $4 \% \mathrm{drift}$, in all the drift levels, the lateral load was zero and prolonged to a particular time due to the crack opening and crack closing phenomenon [Figure 15(a)]. At 4\% drift, first push and pull loading cycles, a detectable local buckling was identified on both sides of the column faces. At $6 \%$ drift level, $70 \mathrm{~mm}$ above the foundation concrete, the local buckling continued. After $6 \%$ Drift, inelastic buckling occurred in the CFST column [Figure 15(b)]. The width of crack around the interface measured at $7 \%$ drift, was $4 \mathrm{~mm}$. The maximum lateral load degraded from $66.9 \mathrm{kN}$ and reached $42.3 \mathrm{kN}$ (about $36.7 \%$ ) at the end of the test.

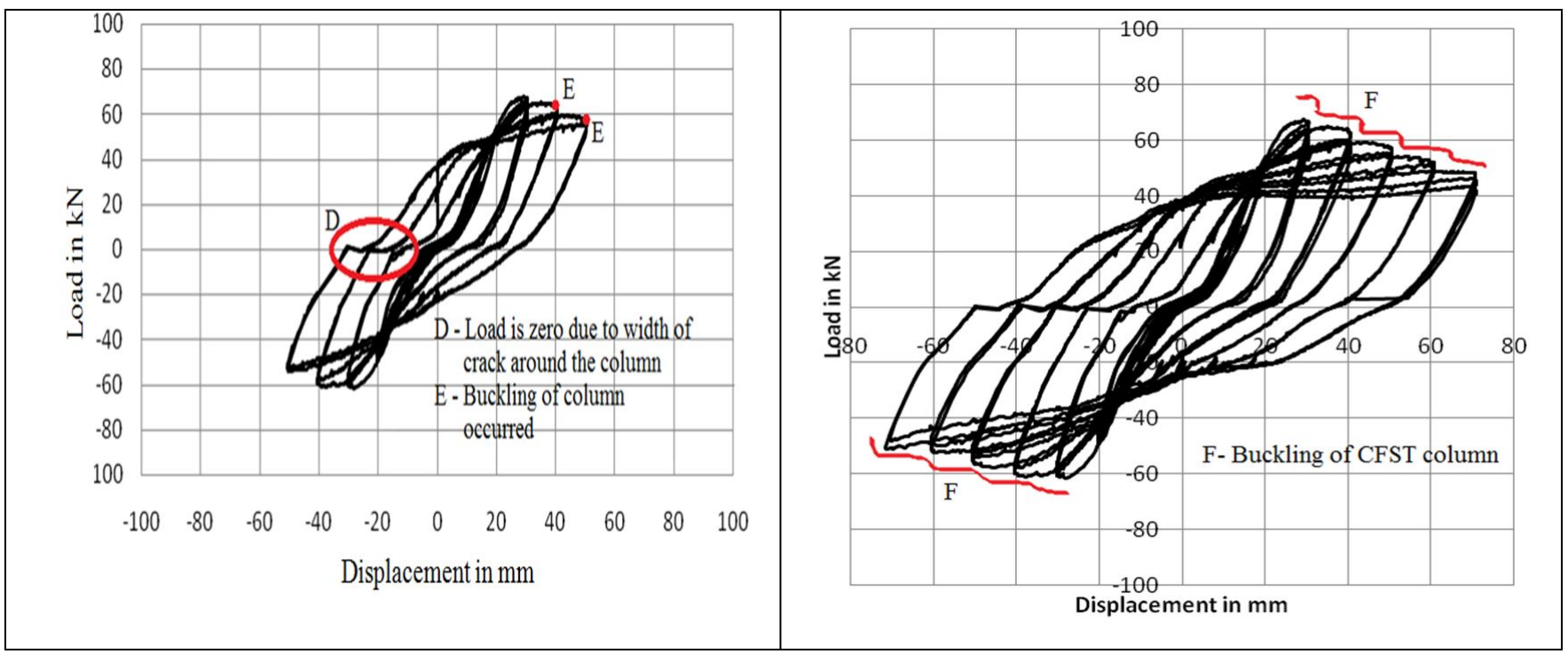

Figure 15 Embedded column - foundation connection CFST-0.75D-4S-03 at (a) 5\% Drift and (b) 7\% Drift.

\subsection{Embedded Column-Foundation Connection CFST-0.75D-8S-04}

The specimen designated as CFST-0.75D-8S-04 is a CFST column-foundation connection with depth of embedment of $0.75 \mathrm{D}$ and with eight number of stiffeners at column-base plate connection as shown in Figure $2(\mathrm{~d})$. Displacement controlled lateral load on the top of column specimen with constant axial load was applied as shown in Figure 4 and 5. The loading history is shown in Figure 6.

The load-displacement response of the connection was in elastic stage upto $1 \%$ drift and for the applied displacement, the loading pattern coincided with the unloading pattern and the corresponding lateral load for $1 \% \mathrm{drift}$ was $53.16 \mathrm{kN}$ [Figure $16(\mathrm{a})$ ]. After $2 \% \mathrm{drift}$, the specimen shifted from elastic to elasto - plastic stage. The specimen 
attained a maximum load of $73.6 \mathrm{kN}$ and sustained upto $3 \%$ drift. Symmetrical relatinship was shown in push and pull side of the load - displacement curve [Figure 16(b)].

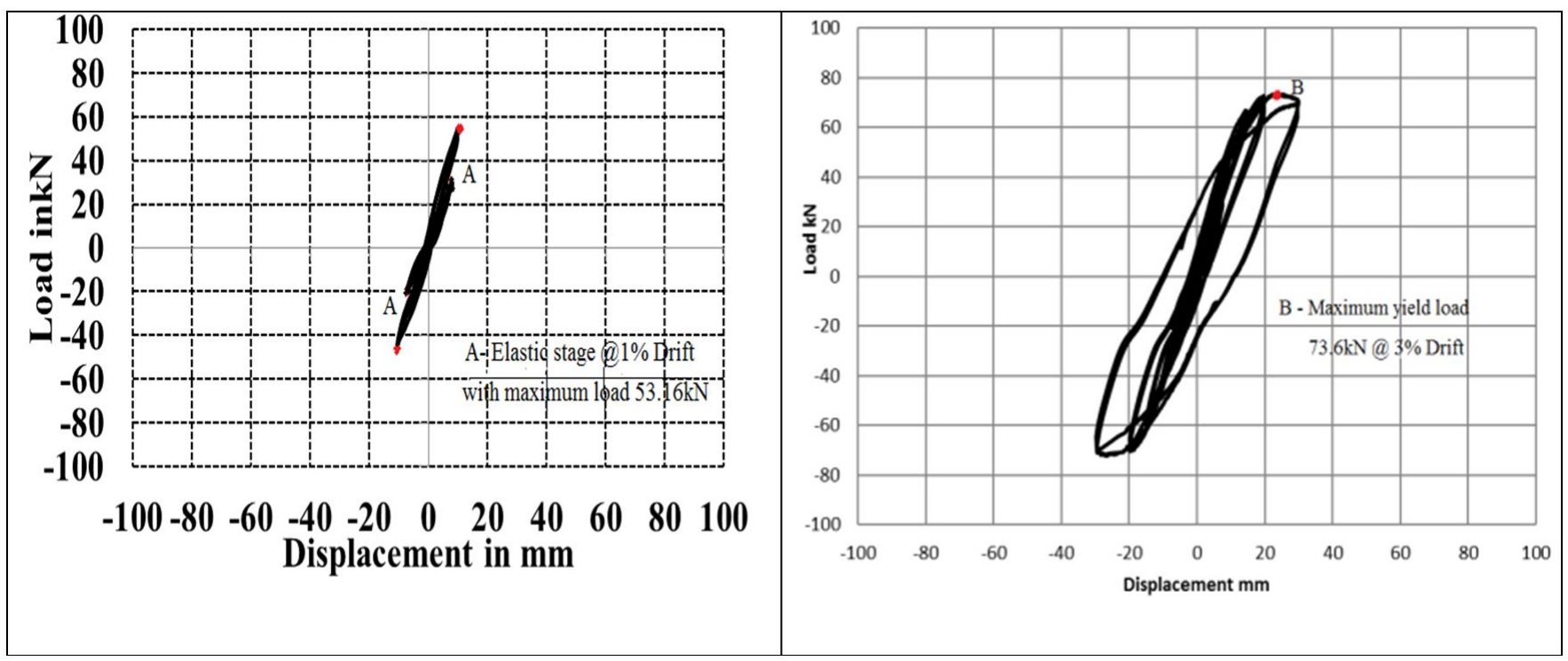

Figure 16 Embedded column - foundation connection CFST-0.75D-8S-04 at a) 1\% Drift and b) 3\% Drift.

Cracks around the column was initiated with minor cracks in the foundation concrete during $3 \%$ drift level. At the 2nd cycle of $4 \%$ drift, elastic bucking of column commenced and the lateral load carrying capacity decreased to $66.38 \mathrm{kN}$. At $5 \%$ drift, the load value was $58.74 \mathrm{kN}$ [Figure $17(\mathrm{a})$ ]. The degraded strength corresponding to the maximum load was $5.3 \%$ and $16.3 \%$ at $4 \%$ and $5 \%$ drift levels respectively. The area under hysteresis curve at further drift levels increased, exhibiting a higher level of dissipated energy. At $5 \%$ drift, elastic buckling of circular column on both sides were prolonged due to alternate loading. Finally, inelastic buckling of the specimen was initiated from 2 nd cycle of $6 \% \mathrm{drift}$. The complete hysteresis curve was shown in [Figure $17(\mathrm{~b})$ ] and the strength degraded from yield load of $73.6 \mathrm{kN}$ to $38.7 \mathrm{kN}$. The degraded strength at the drift $7 \%$ compared with the maximum load was $47.4 \%$.

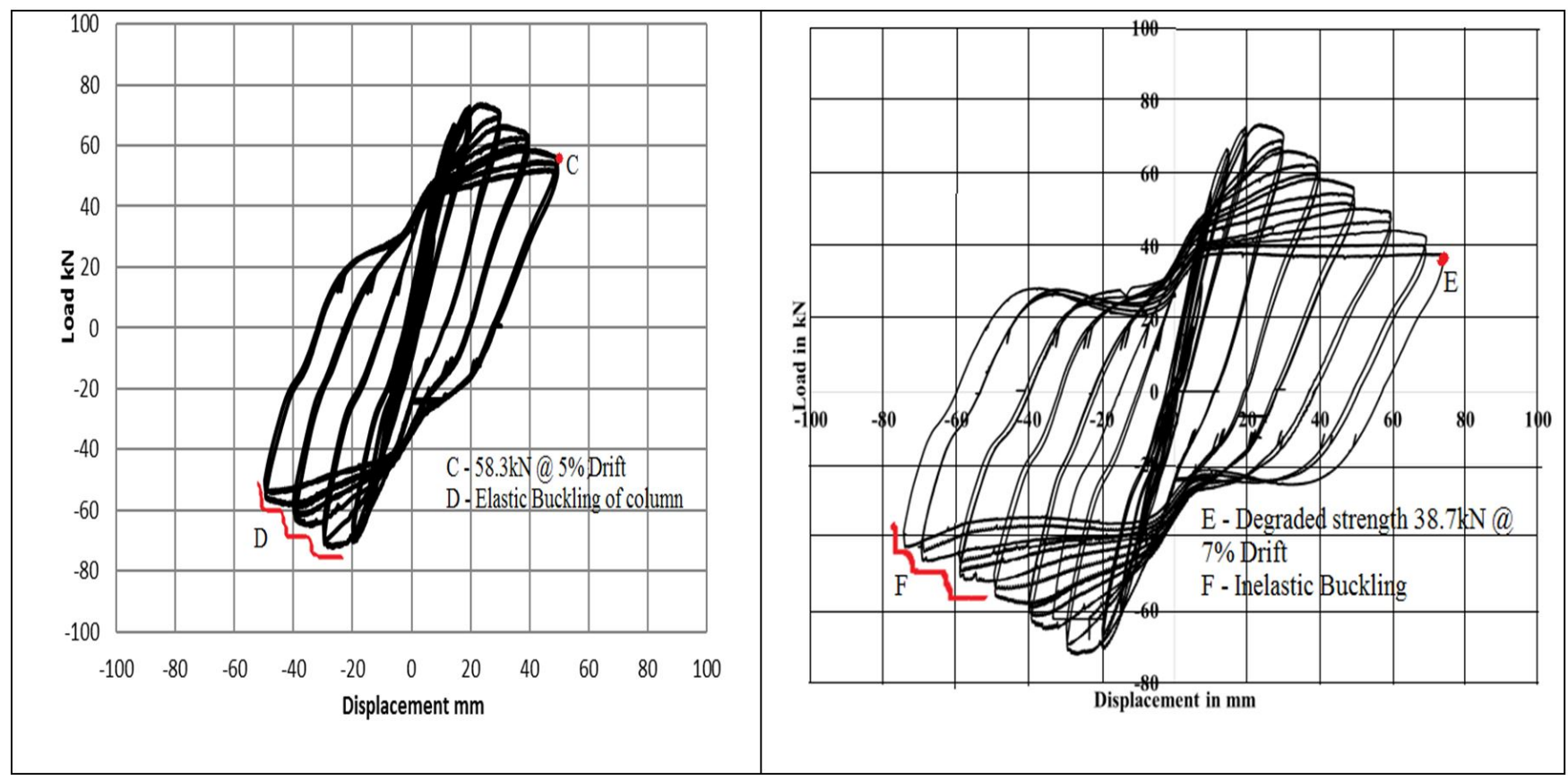

Figure 17 Embedded column - foundation connection CFST-0.75D-8S-04 at (a) 5\% Drift and (b) 7\% Drift. 


\subsection{Embedded Column-Foundation Connection CFST-0.75D-8S-M}

The specimen designated as CFST-0.75D-8S-M-05 is a CFST column-foundation connection with depth of embedment of $0.75 \mathrm{D}$ and with eight number of stiffeners at column-base plate connection. In addition, a layer of mesh around the CFST column was provided with $12 \mathrm{~mm}$ diameter bars as shown in Figure 2(e). Displacement controlled lateral cyclic load on the top of column specimen with constant axial load was applied as shown in Figure 4 and 5 . The loading history is shown in Figurer 6.

Similar to the other connection types, load-deformation curve was linear at initial drift levels. The load-displacement curve during loading and unloading fitted in a straight line [Figure 18(a)]. The energy absorption capacity at this stage was very low. At $2 \%$ drift, there was no significant damage spotted in the specimen. At $3 \%$ drift level, the column foundation connection reached a yield load of $81.6 \mathrm{kN}$ [Figure 18(b)]. This maximum load was extended for two more cycles of loading. After the subsequent cycles, the drop in lateral load was noticed.

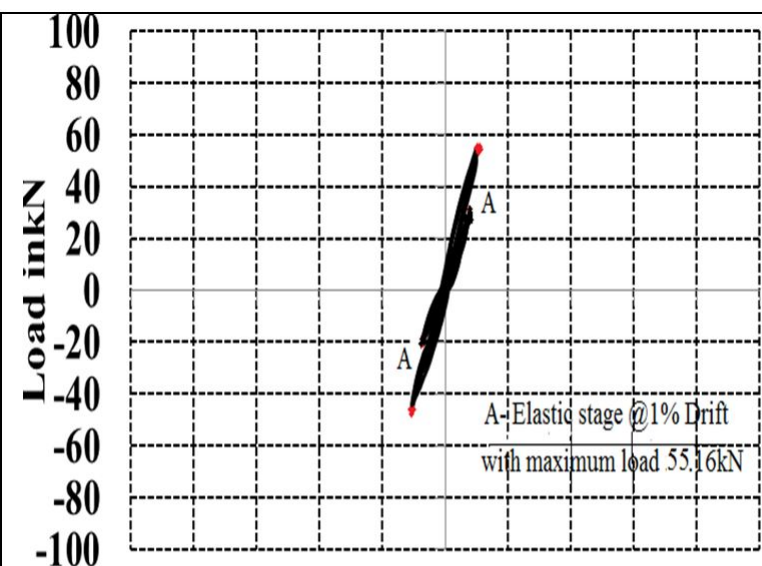

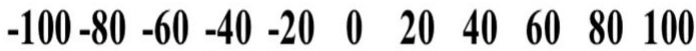
Displacement in $\mathrm{mm}$

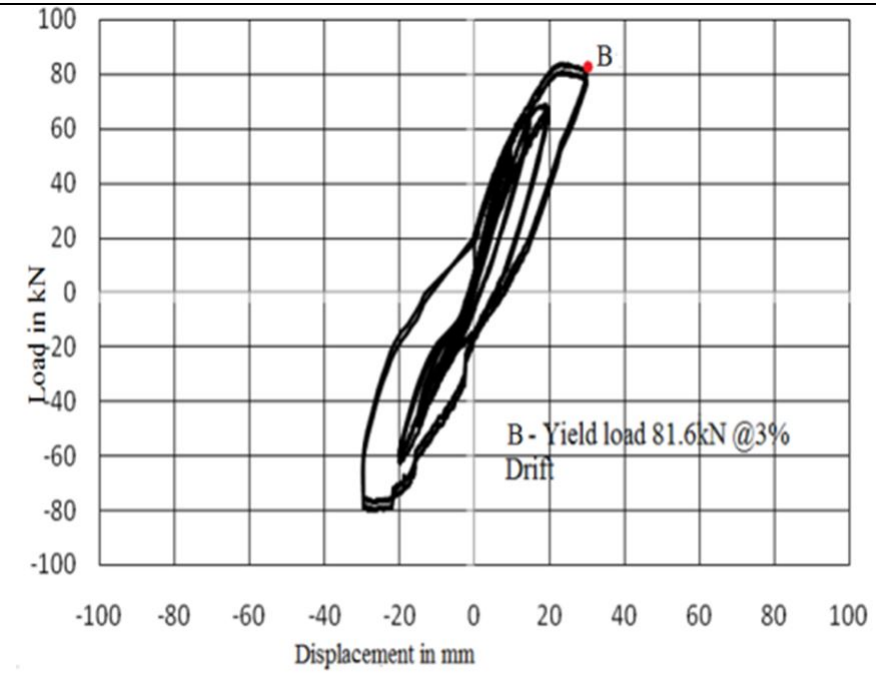

Displacement in mm

Figure 18 Embedded column - foundation connection CFST-0.75D-8S-M-05 at a) 1\% Drift and b) 3\% Drift.

At 2nd cycle of $4 \%$ drift, a small local buckling was found in the CFST column, $25 \mathrm{~mm}$ above the foundation concrete [Figure 19(a)]. When the load was released, the buckling got faded away slowly. This phenomenon was called as elastic buckling. After the following drift levels, the elastic buckling on both side of the column got started and extended till first cycle of $6 \%$ drift. The drop in strength at $7 \%$ drift was $43.7 \mathrm{kN}$. At this drift level, inelastic buckling was observed. Among the five specimens, this connection reached the highest point of the load - displacement curve. The drop in strength was noted as $41.3 \mathrm{kN}$ at the end of test and it was almost $50 \%$ lesser compared with the ultimate load capacity. The 12 step hysteresis loop is presented in Figure 19(b). 


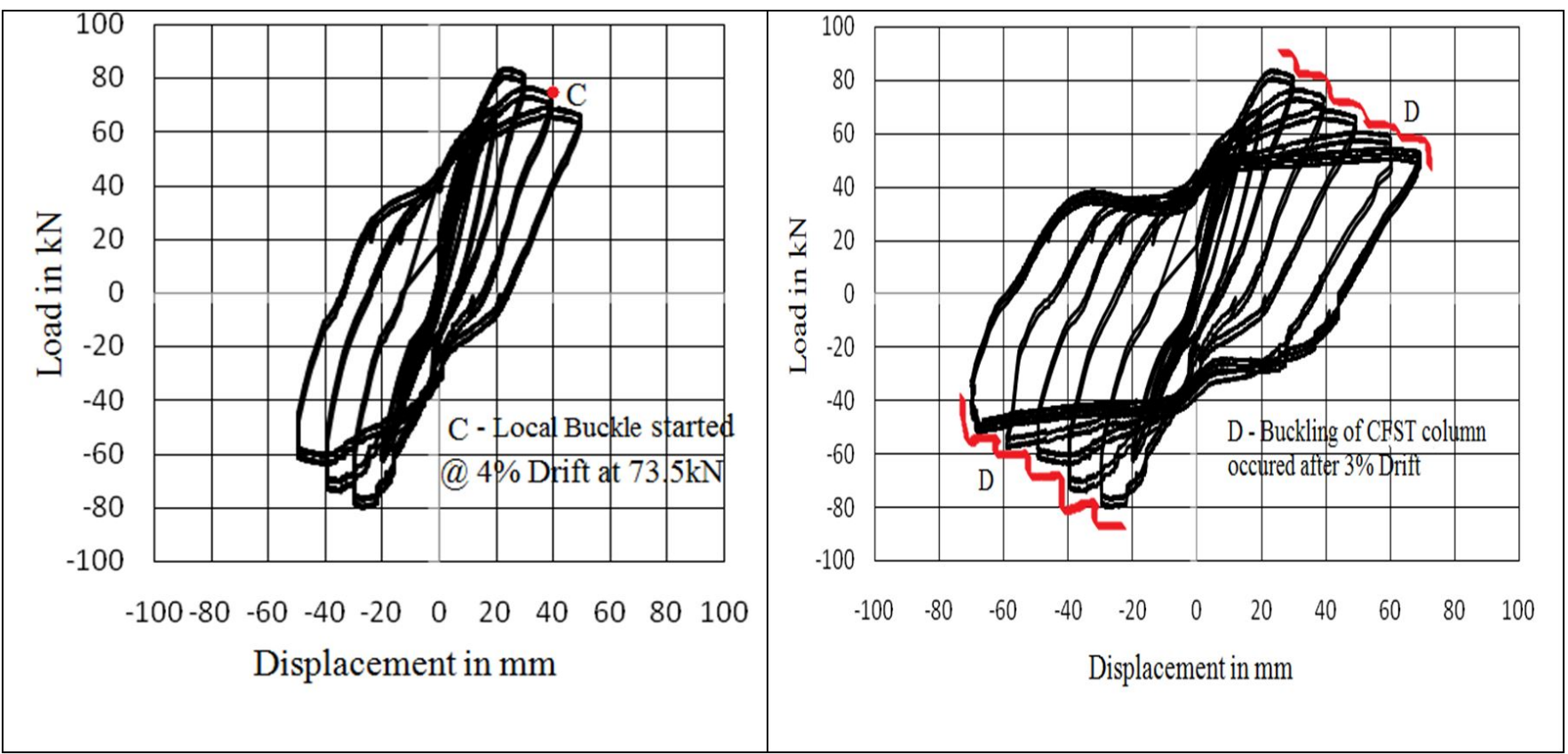

Figure 19 Embedded column - foundation connection CFST-0.75D-8S-M-05 at a) 5\% Drift and b) 7\% Drift.

\section{RESULTS AND DISCUSSION}

\subsection{Comparison of Exposed and Embedded Column Connection}

The behaviour of exposed column foundation connection specimen CFST-0D-4S-01 and embedded connection specimen CFST-1D-4S-02 was compared in Figure 20. From the load-displacement responses of the two specimens, the following results were observed.

In specimen CFST-0D-4S-01, the global failure pattern noted was a) cracks in foundation concrete - In the initial stage, these crack appeared on the top of foundation concrete. b) Cracks between the interface of base plate and foundation concrete - opening and closing phenomenon of cracks were observed, when the direction of load was reversed. c) Yielding of anchor bolts. In embedded connection, the failure pattern noticed include a) minor foundation cracks b) elastic buckling of CFST column c) Inelastic buckling of CFST column.

At the end of the test, bulging of foundation concrete near the column to base plate connection was noticed in specimen CFST-0D-4S-01 and it led to severe damage in foundation concrete. The specimen CFST-1D-4S-02 with 1D embedment depth, the strength was improved and gradual degradation of stiffness occurred when the lateral displacement was increased. From the load- displacement behaviour of specimens CFST-0D-4S-01 and CFST-1D-4S-02, it was pinpointed that the depth of embedment is the greatest influencing parameter in the composite connection design. the specimen CFST-0D-4S-01 and CFST-1D-4S-02 reached the maximum load of 52.6kN, $71.1 \mathrm{kN}$ respectively. The percentage increase between the two specimens corresponding to maximum load was $35.2 \%$. The dissipated energy was calculated for the specimens CFST-0D-4S-01 and CFST-1D-4S-02 are found to be $85 \mathrm{kN}-\mathrm{m}$ and $250 \mathrm{kN}-\mathrm{m}$ respectively. The specimen CFST-1D-4S-02 showed better energy absorption. Hysteresis curve of specimen CFST-0D-4S-01 was very lean. Hence, poor performance was obtained for the specimen CFST-0D-4S-01.

By providing additional depth of embedment in specimen CFST-1D-4S-02, the strength and energy absorption was improved. By providing additional four numbers of stiffeners, the critical section of the connection was shifted from the embedded bolt to the foundation concrete. 


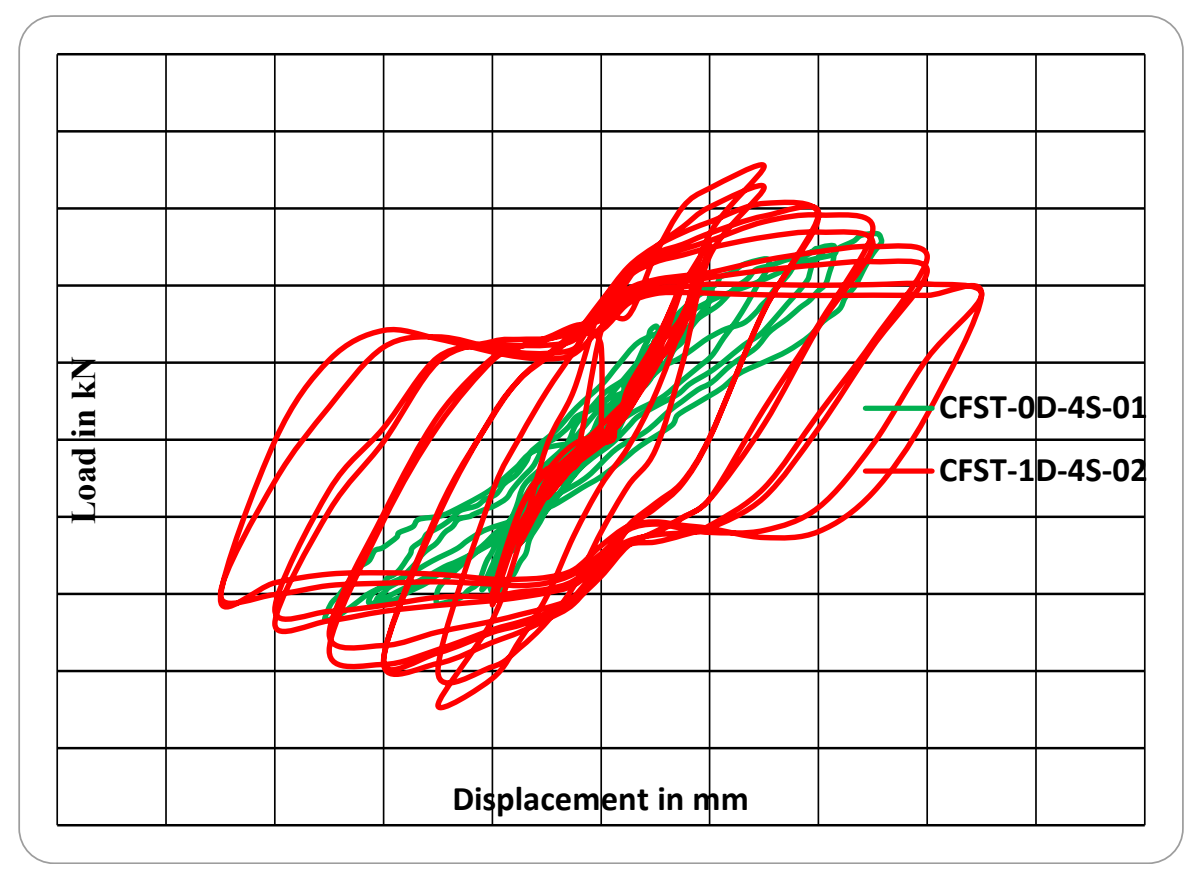

Figure 20 Specimen CFST-0D-4S-01 Vs CFST-1D-4S-02.

\subsection{Parametric Study on Embedded Base Connection}

The behaviour of embedded column foundation connection specimens CFST-1D-4S-02, CFST-0.75D-4S-03, CFST0.75D-8S-04 and CFST-0.75D-8S-M-05 were discussed. The load-displacement response of all the embedded specimens showed the stable spindle shape. Specimen CFST-1D-4S-02 and specimen CFST-0,75D-4S-03 were compared in Figure 21. The specimen CFST-1D-4S-02 exhibited a symmetric behaviour in both the push and pull directions. Where as, in specimen CFST-0.75D-4S-03, due to width of crack opening around the column in pull direction is large, the loaddisplacement cuve is unsymmetrical.

The ultimate load reached by the specimens CFST-1D-4S-02 and specimen CFST-0.75D-4S-03 was 71.1 and $66.9 \mathrm{kN}$. Both the specimens exhibited favourable ductile behaviour. The hysteretic behaviur of specimen CFST-1D-4S-02 was flat when compared to specimen CFST-0.75D-4S-03. The energy dissipation capacity of the specimens CFST-1D-4S-02 and specimen CFST-0.75D-4S-03 are found to be $250 \mathrm{kN}-\mathrm{m}$ and $225 \mathrm{kN}-\mathrm{m}$.

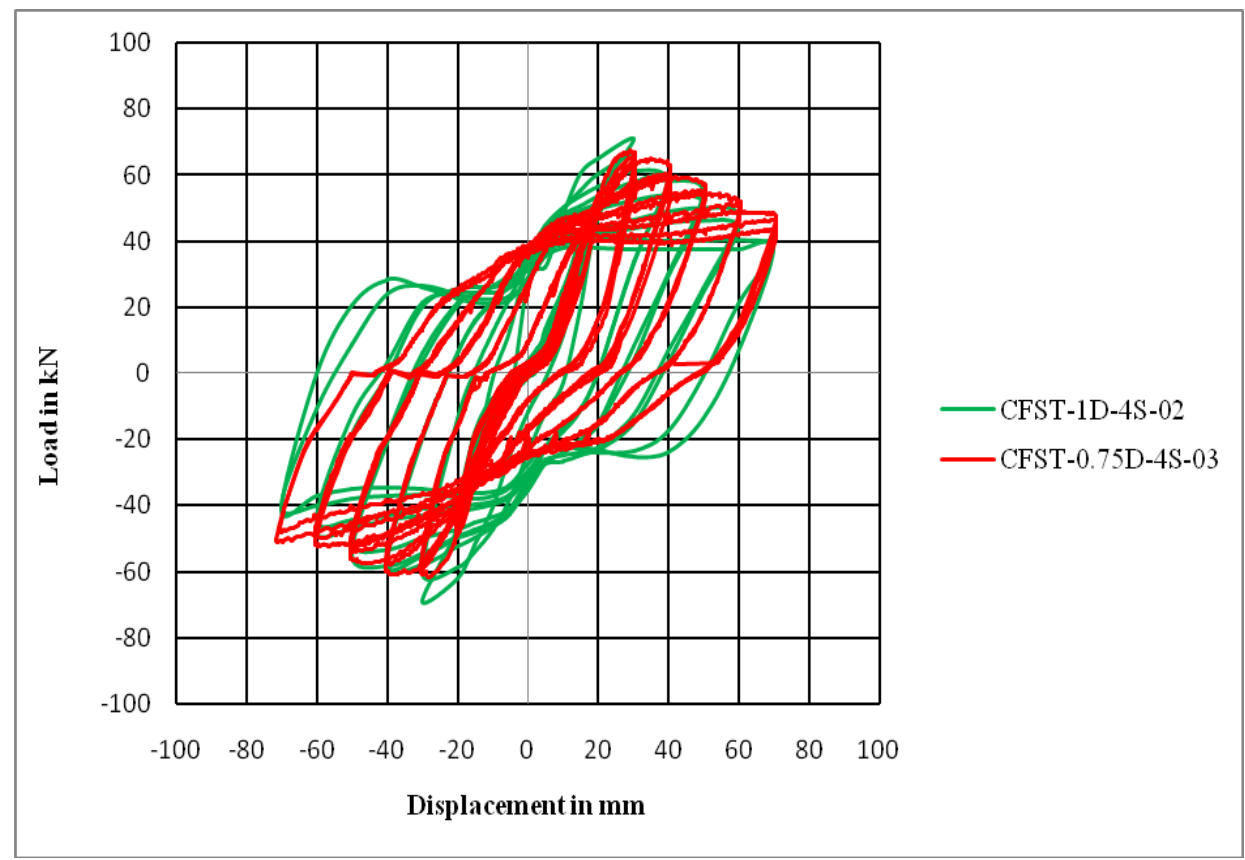

Figure 21 Specimen CFST-1D-4S-02 Vs CFST-0.75D-4S-03. 
From the specimens CFST-1D-4S-02 and CFST-0.75D-4S-03, the column- foundation connection with deeper depth of embedment behaved well. To improve the connection with less embedment depth, additional number of stiffeners were provided in specimen CFST-0.75D-8S-04. Figure 22 represents the load- displacement response of the specimens CFST-0.75D-4S-03 and CFST-0.75D-8S-04 respectively.

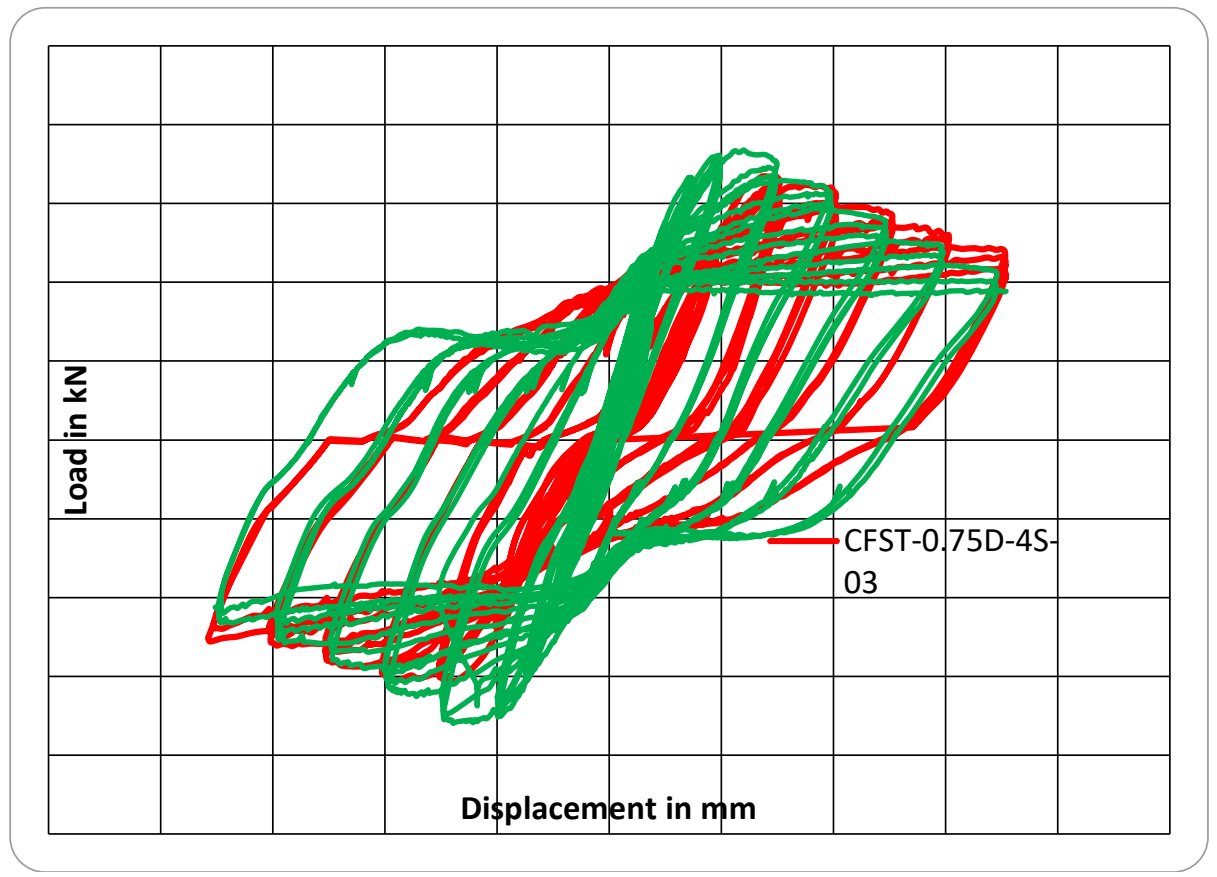

Figure 22 Specimen CFST-0.75D-4S-03 Vs CFST-0.75D-8S-04.

The specimen CFST-0.75D-8S-04 reached the maximum yield load of $73.6 \mathrm{kN}$ at $3 \%$ drift. At the same drift level, the specimen CFST-0.75D-4S-03 marked the maximum load of $66.9 \mathrm{kN}$. The strength of the specimen CFST-0.75D-8S-04 increased up to $10 \%$ compared to the specimen CFST-0.75D-4S-03. After reaching the ultimate load, with the incresed displacement, the strength degradation was also incresed in both the specimens. The energy dissipation capacity of the specimens CFST-0.75D-4S-03 and CFST-0.75D-8S-04 are found to be $250 \mathrm{kN}-\mathrm{m}$ and $256 \mathrm{kN}-\mathrm{m}$ respectively. From the results, the specimen with less embedment depth and incresed number of stiffeners in CFST-0.75D-8S-04 exhibited improved performance than specimen with deeper embement depth with lesser number of stiffeners in CFST-0.75D-4S03. When specimen CFST-0.75D-8S-04 was compared with the specimen CFST-1D-4S-02, both the specimens exhibited similar performance. A small improvement was noticed in CFST-0.75D-8S-04. The increased number of stiffeners is also the infuencing parameter in embedded CFST column - foudation connection.

To improve the performance of the specimen CFST-0.75D-8S-04 with the same embedment depth, an additonal layer of mesh was provided around the CFST column in specimen CFST-0.75D-8S-M-05 and the comparison of results are shown in Figure 23. 


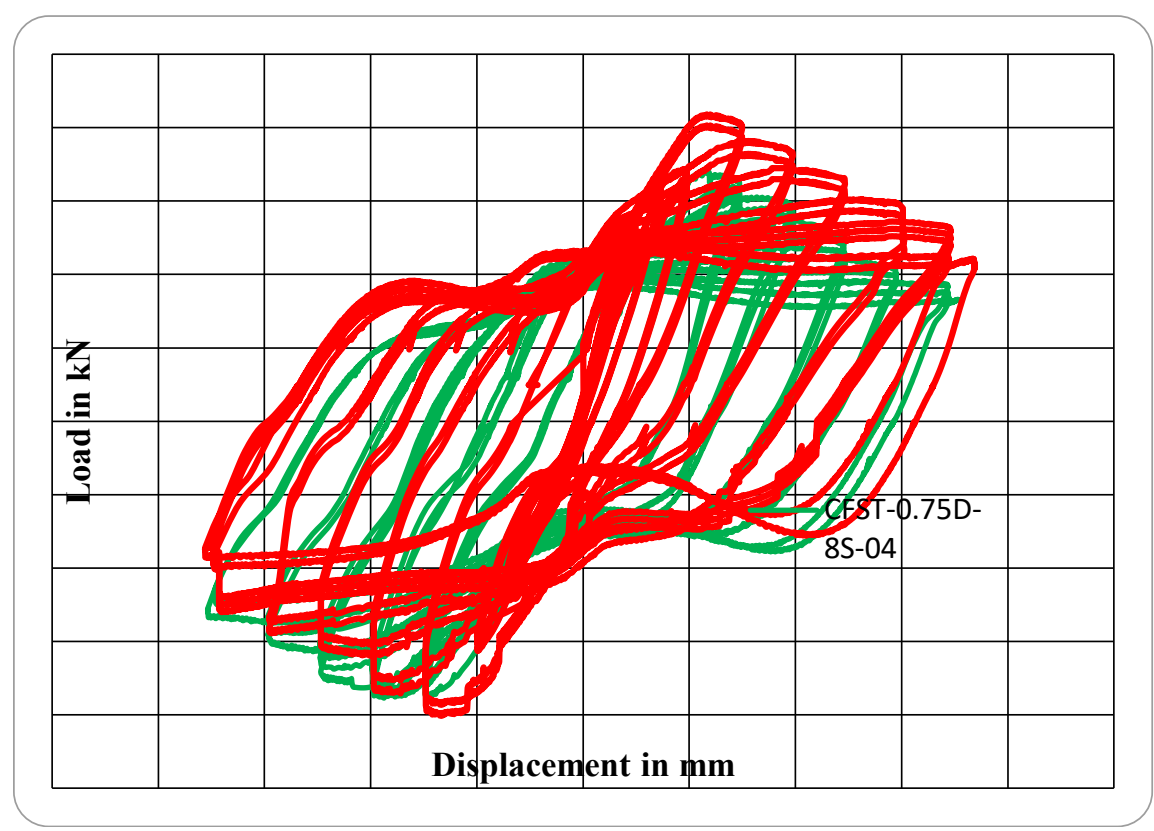

Figure 23 Specimen CFST-0.75D-8S-04 Vs CFST-0.75D-8S-M-05.

At 3\% Drift, CFST-0.75D-8S-04 reached the yield load of 73.6kN. At the same drift level, specimen CFST-0.75D-8SM-05 reached the maximum load of $81.6 \mathrm{kN}$. Significant energy dissipation was exhibited in both the specimens. The caculated dissipated energy of specimen CFST-0.75D-8S-04 and CFST-0.75D-8S-M-05 were found to be $255 \mathrm{kN}-\mathrm{m}$ and $282 \mathrm{kN}-\mathrm{m}$ respectively. The minimum damage to the foundation concrete was noticed at the end of the test in both the specimens.

\subsection{Connections with same number of Stiffeners}

The specimens CFST-0D-4S-01, CFST-1D-4S-02 and CFST-0.75D-4S-03 had 4 number of stiffeners with different depth of embedment. The ultimate load reached by the specimens were $52.6 \mathrm{kN}, 71.1 \mathrm{kN}$ and $66.9 \mathrm{kN}$ respectively. Compared with the specimen CFST-0D-4S-01, maximum strength was increased when the specimen embedded up to the depth of $0.75 \mathrm{D}$ about $27.2 \%$ and when the specimen was embedded up to the depth of 1D CFST-1D-4S-02 35.1\%. The dissipated energy of the specimens CFST-0D-4S-01, CFST-1D-4S-02 and CFST-0.75D-4S-03 were 85kN-m, 250kN-m and $225 \mathrm{kN}-\mathrm{m}$. By increasing the embedded depth of CFST column, the connection strength was improved in specimen CFST1D-4S-02.

\subsection{Connections with same Embedment Depth 0.75D}

The specimens CFST-0.75D-4S-03, CFST-0.75D-8S-04 and CFST-0.75D-8S-M-05 had different stiffener arrangement with same embedment depth. The specimens achieved the maximum load of $66.9 \mathrm{kN}, 73.6 \mathrm{kN}$ and $81.6 \mathrm{kN}$ respectively. In all the specimens, the CFST column reached its full capacity. Failure of connections were due to the inelastic buckling of CFST columns. The percentage increase in the specimens compared to CFST-0.75D-4S-03 were $10 \%$ when the specimen CFST-0.75D-8S-04 with increased number of stiffeners and $21.9 \%$ when the specimen CFST-0.75D-8S-M-05 with increased number of stiffeners and a layer of mesh around the column. The caculated dissipated energy of specimens CFST-0.75D-4S-03, CFST-0.75D-8S-04 and CFST-0.75D-8S-M-05 were found to be $225 \mathrm{kN}-\mathrm{m}, 255 \mathrm{kN}-\mathrm{m}$ and $282 \mathrm{kN}-\mathrm{m}$. Comparing the performance of all the specimens, the specimen with $0.75 \mathrm{D}$ embedded depth with mesh around the column in CFST-0.75D-8S-M-05 exhibited a promising performance in terms of strength and energy dissipation capacity.

\subsection{Strength Characteristics}

The energy dissipation capacity of all the specimens is as shown in Figure 24. It can be seen that specimen CFST-0D4S-01 has shown poor performance in terms of energy dissipation. When stiffeners were increased, significant improvement in the energy dissipating performance in all the specimens. 


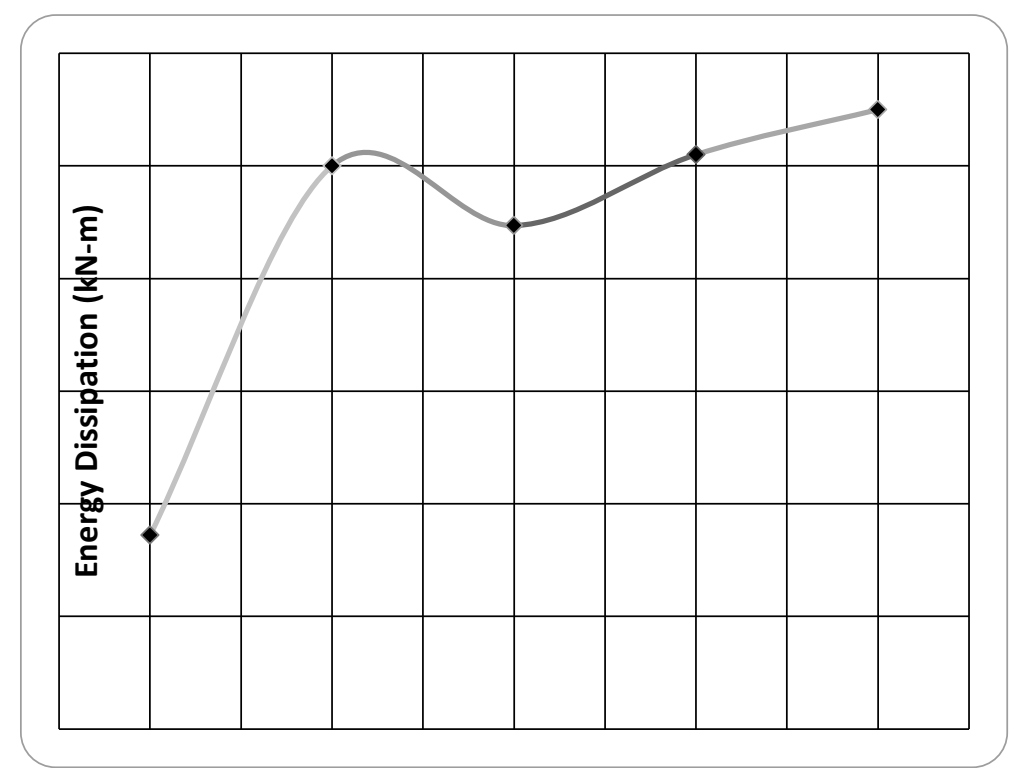

Figure 24 Energy dissipation capacity.

By providing a simple mesh arrangement with stiffeners around the column, the efficiency of the base connection is improved. The energy absorption has increased around $70 \%$ by providing the mesh reinforcement in specimen CFST0.75D-8S-M-05 with exposed column foundation connection specimen CFST-0D-4S-01.

\section{CONCLUSIONS}

Exposed and embedded CFST column to foundation connection with varying depth of embedment and number of stiffeners under lateral cyclic loading were tested experimentally and the following conclusions were made:

1. The failure pattern of exposed connection was mainly due to yielding of anchor bolts where as in embedded connection specimens, the failure was due to inelastic buckling of the CFST column. All the specimens achieved a ductile behaviour with minimum damage of concrete foundation.

2. The load- displacement response of the specimen CFST-0D-4S-01 showed pinched shape. All the embedded specimens showed spindle shape.

3. The axial load applied did not affect the behviour of the column foundation connection.

4. A simple layer of mesh with additional stiffeners around the column, the embedment depth of the column foundation connection was reduced and this specimen reached the maximum yield load compared to other specimens. So the embedment depth was optimized to 0.75D.

5. Parametric study was carried out on embedded column foundation connection with varying the depth of embedment, number of stiffeners and a layer of mesh around the column. Among all the specimens, the specimen CFST-0.75D-8S-M-05 was found to be better in terms of strength and energy dissipation capacity. This proposed connection is simple to use in field applications and also has better performance against lateral loading.

Author's Contributions: Conceptualization, Jothimani B and Umarani C; Methodology, Jothimani B; Investigation, Jothimani B and Umarani C; Writing - original draft, Jothimani B; Writing - review \& editing, Jothimani B and Umarani C; Funding acquisition, Jothimani B and Umarani C; Resources, Jothimani B; Su-pervision, Umarani C.

Editor: Marcílio Alves.

\section{References}

Faschan, W. (1992). "The Bank of China, Advancing the Art of Composite Construction." Composite Construction of Steel and Concrete IIASCE, 576. 
Furlong, R. W. (1967). "Strength of Steel-Encased Concrete Beam Columns." Journal of Structural Division ASCE 93(ST5), 113124.

Hsu, H-L and H-W. Lin (2006). "Improving seismic performance of concrete-filled tube to base connections." Journal of Constructional Steel Research 62(12): 1333-1340.

Jiho Moon., Charles W. Roeder., Dawn E. Lehman and Hak-Eun Lee (2012). “Analytical modeling of bending of circular concrete-filled steel tubes", Engineering Structures 42: 349-361.

Jiho Moon., Dawn Lehman., Charles W. Roeder and Hak-Eun Lee (2013). "Evaluation of embedded concrete-filled tube (CFT) column-to-foundation connections." Engineering Structures 56: 22-35.

Julia Marson and Michel Bruneau. M., (2004). "Cyclic testing of concrete-filled circular steel bridge piers having encased fixedbased detail." Journal of Bridge Engineering ASCE 9.1: 14-23.

Knowles, R. and Park. R. (1970). "Axial Load Design for Concrete Filles Steel Tubes.” Journal of the Structural Division. ASCE 96(10): 2125-2153.

M. Tomii, K. Yoshimura and Y. Morishita (1977). "Experimental studies on concrete filled steel tubular stub columns under concentric loading." Proc. of the International Colloquium on Stability of Structures under Static \& Dynamic Loads. Washington, SSRC/ASCE: 718-41.

Pertold J., Xiao RY. and Wald F. (2000). "Embedded steel column bases I experiments and numerical simulation." Journal of Constructional Steel Research 56: 253-7.

P.K. Neogi, H.K., Sen and J.C. Chapman (1969). "Concrete-filled tubular steel columns under eccentric loading." The Structural Engineer 47(5): 187-95.

Shuichi Matsumoto., Osamu Hosozawa., Hiroyuki Narihara., Tsutomu Komuro and Shin-ichiro Kawamoto (2014)."Structural design of an ultra High-rise building using concrete filled steel tubular column with $780 \mathrm{~N} / \mathrm{mm}^{2}$ class high strength steel and $F_{c}$ $150 \mathrm{~N} / \mathrm{mm}^{2}$ high strength concrete." International Journal of High-rise Buildings 3(1): 73-79.

Toko Hitaka., Keiichiro Suita and Mikiko. Kato (2003). "Design and Construction of Concrete-Filled Steel Tube Column System in Japan." Earthquake Engineering and Engineering Seismology 4(1): 51-73.

Viest, I. (1992). “Composite Construction Recent Past, Present,and Near Future." Composite Construction of Steel and Concrete II ASCE: 1-16.

Yao Cui., Hao Liu and Hao Li (2015). "Shear Behavior of Exposed Column Base Plate Connections." 6th International Conference on Advances in Experimental Structural Engineering University of Illinois, Urbana-Champaign, United States. 